\title{
Twenty-year experience with extracorporeal life support as bridge to lung transplantation
}

\author{
Alberto Benazzo, MD, ${ }^{\mathrm{a}}$ Stefan Schwarz, MD, ${ }^{\mathrm{a}}$ Florian Frommlet, $\mathrm{PhD},{ }^{\mathrm{c}}$ Thomas Schweiger, MD, PhD, ${ }^{\mathrm{a}}$ \\ Peter Jaksch, MD, ${ }^{a}$ Peter Schellongowski, MD, ${ }^{\mathrm{b}}$ Thomas Staudinger, MD, ${ }^{\mathrm{b}}$ Walter Klepetko, MD, ${ }^{\mathrm{a}}$ \\ György Lang, MD, PhD, ${ }^{\mathrm{a}, \mathrm{d}}$ and Konrad Hoetzenecker, $\mathrm{MD}, \mathrm{PhD},{ }^{\mathrm{a}}$ the Vienna ECLS Program
}

\section{ABSTRACT}

Objectives: Extracorporeal life support is increasingly used to bridge deteriorating candidates to lung transplantation. Nevertheless, only few systematic reports with a limited number of patients exist describing this practice and its changes over time.

Methods: We retrospectively reviewed our institutional database and performed an era analysis to identify trends over time and risk factors for mortality. After applying propensity score matching, outcomes of bridged patients were compared with those of standard lung transplantation recipients.

Results: Extracorporeal life support was used in 120 patients as an intention to bridge to lung transplantation. Eleven patients $(9.2 \%)$ were bridged between 1998 and 2004, 39 patients $(32.5 \%)$ were bridged between 2005 and 2010, and 70 patients were bridged $(58.3 \%)$ between 2010 and 2017 . In the first era, the main bridging modality was venoarterial-extracorporeal membrane oxygenation ( $\mathrm{n}=10,90.9 \%$ ), whereas venovenous devices were primarily used in later eras (second era: $\mathrm{n}=18,46.2 \%$; third era: $\mathrm{n}=39,55.8 \%$ ). In the second and third eras, 9 patients $(23.1 \%)$ and 24 patients $(34.3 \%)$ could be bridged awake. Short-term outcome was poor in the first era, with only $36.4 \%$ of patients discharged alive but improved in later eras $(53.8 \%$ and $77.1 \% ; P=.002)$. Extracorporeal life support-bridged patients showed an impaired short-term outcome compared with standard recipients. However, survival conditional on 90 days did not differ among the groups $(P=.178)$. In univariate and multivariate analyses, awake extracorporeal life support was protective for survival, whereas acute retransplantation was a risk factor for mortality.

Conclusions: Over the past 2 decades, the role of extracorporeal life support bridging evolved from an acute rescue therapy to a semi-elective procedure. Stratified outcome analysis revealed that extracorporeal life support bridging yielded similar long-term survival compared with nonbridged patients. (J Thorac Cardiovasc Surg 2019;157:2515-25)

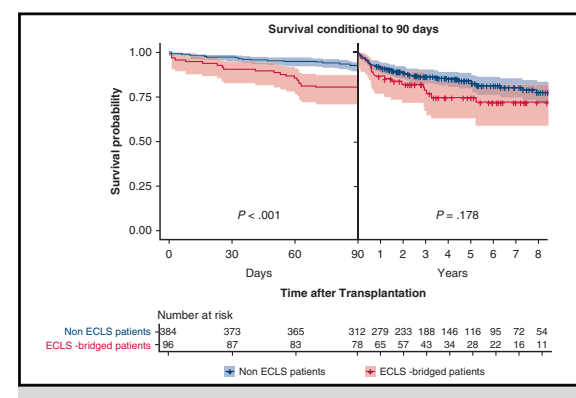

Survival curve conditional on survival to 90 days of propensity-matched groups $(P=.178)$.

\section{Central Message}

Within the last 20 years, ECLS bridging has evolved from an experimental strategy for desperate situations to a semi-elective therapeutic approach for deteriorating transplant candidates.

\section{Perspective}

ECLS is increasingly used to bridge patients to lung transplantation; however, few large singlecenter series describe this practice. Based on a unique patient cohort, this work analyzes the development of ECLS bridging over time, highlighting different aspects of the management of this challenging group of patients.

See Commentary on page 2526.
Over the last decade, the shortage of donor organs has led to constantly increasing waiting times for lung transplantation with a higher risk of acute deterioration for patients on the waiting list. Historically, mechanical ventilation was used as a bridging strategy for these patients; however,

\footnotetext{
From the a Division of Thoracic Surgery, Department of Surgery, Medical University of Vienna, Vienna, Austria; ${ }^{\mathrm{b}}$ Division of Intensive Care Unit, Department of Internal Medicine I, Medical University of Vienna, Vienna, Austria; ${ }^{c}$ Institute for Medical Statistics, CEMSII, Medical University of Vienna, Vienna, Austria; ${ }^{\mathrm{d}}$ Department of Thoracic Surgery, Semmlweis University and National Institute for Oncology, Budapest, Hungary; and ${ }^{\mathrm{e}}$ Department of Anaesthesia, Intensive Care Medicine and Pain Medicine, Medical University of Vienna, Vienna, Austria. This study was presented at the 37th Annual Meeting of the International Society of Heart and Lung Transplantation, San Diego, California, April 5-8, 2017. G.L. and K.H. contributed equally.
}

mechanical ventilation is associated with an increased risk of infection, muscular deconditioning, and functional impairment of other organs. ${ }^{1-6}$

Extracorporeal life support (ECLS) was first reported to rescue deteriorating lung transplant candidates in the

Vienna ECLS Program: B. Moser, MD, PhD, ${ }^{\mathrm{a}} \mathrm{J}$. Matilla Sigueenza, MD, ${ }^{\mathrm{a}} \mathrm{J}$. Horvath, C. Krenn, MD, ${ }^{\mathrm{d}}$ A. Bacher, ${ }^{\mathrm{d}}$ D.M. Baron, MD, ${ }^{\mathrm{d}}$ P. Faybik, MD, ${ }^{\mathrm{d}}$ S. Taghavi, MD. Received for publication June 30, 2018; revisions received Jan 21, 2019; accepted for publication Feb 9, 2019; available ahead of print March 25, 2019.

Address for reprints: Konrad Hoetzenecker, MD, PhD, Division of Thoracic Surgery, Medical University of Vienna, Waehringer Guertel 18-20, A-1090 Vienna, Austria (E-mail: konrad.hoetzenecker@meduniwien.ac.at).

0022-5223/\$36.00

Copyright $(\subset) 2019$ by The American Association for Thoracic Surgery https://doi.org/10.1016/j.jtcvs.2019.02.048 


\section{Abbreviations and Acronyms \\ ECCO2- $\mathrm{R}=$ extracorporeal $\mathrm{CO} 2$ removal \\ ECLS = extracorporeal life support \\ ECMO = extracorporeal membrane oxygenation \\ iLA $\quad=$ interventional lung assist \\ $\mathrm{PA} / \mathrm{LA}=$ pulmonary artery/left atrium \\ $\mathrm{PCO}_{2}=$ carbon dioxide tension \\ PGD = primary graft dysfunction \\ $\mathrm{VA} \quad=$ venoarterial \\ $\mathrm{VV}=$ venovenous}

assist (iLA) systems (Xenios AG, Heilbronn, Germany) or more recently by iLA-ActiVVe, a venovenous (VV) system incorporating a miniaturized pump and a gas exchange membrane (iLA) optimized for low to moderate blood flow together with a single venous cannulation with a $22 \mathrm{~F}$ to $24 \mathrm{~F}$ double-lumen cannula (Novaport Twin, Xenios AG, Heilbronn, Germany). The same device was used for hypercapnic respiratory failure with concomitant mild hypoxemia. In case of severe hypoxic respiratory failure, a VV extracorporeal membrane oxygenation (ECMO) with a 2-site (femoro-jugular) or single-site large-bore double-lumen cannula from $27 \mathrm{~F}$ to $31 \mathrm{~F}$ (Avalon Laboratories, Los Angeles, Calif) configuration was used. In hemodynamically unstable patients, a femoro-femoral venoarterial (VA) ECMO using $17 \mathrm{~F}$ to $19 \mathrm{~F}$ drainage and $15 \mathrm{~F}$ to $17 \mathrm{~F}$ reperfusion cannulas was inserted (all Bio-Medicus Cannula, Medtronic Inc, St Paul, Minn). In selected cases, a femoro-subclavian or a jugular-subclavian access was used. The ECMO circuit consisted of a conventional centrifugal pump (Medtronic BioConsole 560, Medtronic Inc, or Cardiohelp, Maquet, Rastatt, Germany) combined with a hollow-fiber oxygenator (Medtronic CPMPCB Affinity BPX-80 or Affinity NT; Medtronic Inc, or Quadrox, Maquet Rastatt). In 1 case of differential hypoxia (watershed phenomenon, harlequine's syndrome) a veno-arteriovenous ECMO configuration was established with a second injection cannula delivering saturated blood into the jugular vein. In 2 patients with pulmonary hypertension and supra-systemic pressures, a pulmonary artery to left atrium (PA/LA) Novalung (Xenios, New York, $\mathrm{NY)}$ was used. ${ }^{12}$ A PA/LA Novalung was inserted in general anesthesia through a left anterolateral thoracotomy with temporary peripheral VA ECMO support. The indication for ECLS was reevaluated on a daily basis, and the bridging modality was upgraded or downgraded whenever necessary. The reason for an upgrade from VV to VA was hemodynamic instability in most patients. This was defined as increased dose of noradrenaline, increased lactate levels, or severe hypotension. Patients requiring an upgrade from ECCO2-R to VV ECMO had a deterioration of their blood gases (oxygen tension $<80 \mathrm{~mm} \mathrm{Hg}$ or $\mathrm{PCO}_{2}>70 \mathrm{~mm} \mathrm{Hg}$ ). Most patients stabilized after upgrading their ECLS system to a high-flow VV ECMO. Patients were anticoagulated with continuous infusion of Naheparin targeting for activated partial thromboplastin time between 55 and 65 seconds or with therapeutic twice per day subcutaneous lowmolecular weight heparin, aiming for anti-Xa levels of 0.3 to $0.7 \mathrm{IU} / \mathrm{mL}$. As soon as hemodynamic and respiratory stability were reestablished, sedation was gradually reduced and patients were weaned from the ventilator if possible. Physiotherapy was started as soon as possible in awake patients.

All recipients followed our standard post-transplant protocol until death, including regular follow-up visits, surveillance bronchoscopies, pulmonary function tests, computed tomography scans, and blood examinations. Additional diagnostic transbronchial biopsies, bronchoalveolar lavage, and computed tomography scans were performed in case of lung function deterioration.

Primary graft dysfunction (PGD) grade was calculated 72 hours after transplantation according to the latest recommendation of the International Society for Heart and Lung Transplantation working group. ${ }^{13}$ Patients were graded on the basis of chest $\mathrm{X}$-rays and $\mathrm{P} / \mathrm{F}$ ratio. For patients on prolonged postoperative ECMO 72 hours after transplantation with a normal chest $\mathrm{x}$ ray, an "ungradable" PGD grade was assigned. In case of bilateral infiltrations consistent with a reperfusion edema, grade 3 was assumed.

\section{Statistical Analysis}

Categorical variables are reported as percentage, and continuous variables are reported as median (interquartile range, min-max). Chi-square tests, Fisher exact tests, Mann-Whitney $U$ tests, and analysis of variance were used to compare variables. A $P$ value $<.05$ was considered statistically significant. To analyze trends over time, the study period was divided in 3 time intervals of 6 to 7 years: first era 1998 to 2004, second era 2005 to 2010, and third era 2010 to 2017. The choice of the time intervals was based on 3 different phases of ECLS bridging reflecting the clinical evolution of ECLS concepts. The particularity of the first era was the use of ECLS to 
TABLE 1. Era characteristics

\begin{tabular}{|c|c|c|c|c|}
\hline & $\begin{array}{c}1998-2004 \\
(n=11)\end{array}$ & $\begin{array}{c}2005-2010 \\
(n=39)\end{array}$ & $\begin{array}{c}2010-2017 \\
(n=70)\end{array}$ & $\begin{array}{c}\text { Inter-era } \\
\text { comparison } P \text { value }\end{array}$ \\
\hline Median age (IQR, min-max) & $35(28-51,13-65)$ & $31(24-45,14-66)$ & $36(25-51,8-68)$ & .866 \\
\hline \multicolumn{5}{|l|}{ Gender } \\
\hline Male & $4(36.4 \%)$ & $14(35.9 \%)$ & $33(47.1 \%)$ & \multirow[t]{2}{*}{.476} \\
\hline Female & $7(63.6 \%)$ & $25(64.1 \%)$ & $37(52.9 \%)$ & \\
\hline \multicolumn{5}{|l|}{ Underlying diagnosis } \\
\hline COPD & 0 & $2(5.1 \%)$ & $1(1.4 \%)$ & \multirow[t]{8}{*}{$<.001$} \\
\hline Interstitial lung disease & 0 & $8(20.5 \%)$ & $20(30 \%)$ & \\
\hline $\mathrm{CF}$ & $3(27.3 \%)$ & $14(35.9 \%)$ & $27(38.6 \%)$ & \\
\hline PPH & 0 & $4(10.3 \%)$ & $7(10 \%)$ & \\
\hline ARDS & 0 & $4(10.3 \%)$ & $3(4.3 \%)$ & \\
\hline CLAD & 0 & $7(17.9 \%)$ & $9(12.9 \%)$ & \\
\hline POF & $8(72.7 \%)$ & 0 & 0 & \\
\hline Others & 0 & 0 & $2(2.9 \%)$ & \\
\hline \multicolumn{5}{|l|}{ Bridging goal } \\
\hline Bridge to primary LTx & $3(27.3 \%)$ & $32(82.1 \%)$ & $61(87.1 \%)$ & \multirow[t]{3}{*}{$<.001$} \\
\hline Bridge to elective ReTx & 0 & $7(17.9 \%)$ & $9(12.9 \%)$ & \\
\hline Bridge to acute ReTx & $8(72.7 \%)$ & 0 & 0 & \\
\hline \multicolumn{5}{|l|}{ Bridging indication } \\
\hline Hypoxic respiratory failure & $7(63.6 \%)$ & $8(20.5 \%)$ & $13(18.6 \%)$ & \multirow[t]{3}{*}{$<.001$} \\
\hline Hypercapnic respiratory failure & $1(9.1 \%)$ & $26(66.7 \%)$ & $54(77.1 \%)$ & \\
\hline Combined hemodynamic and respiratory failure & $3(27.3 \%)$ & $5(12.8 \%)$ & $3(4.3 \%)$ & \\
\hline \multicolumn{5}{|l|}{ Ventilation before bridging } \\
\hline Invasive ventilation & $10(90.9 \%)$ & $32(82.1 \%)$ & $48(68.7 \%)$ & \multirow[t]{2}{*}{.131} \\
\hline Noninvasive ventilation & $1(9.1 \%)$ & $7(17.9 \%)$ & $22(31.4 \%)$ & \\
\hline Tracheostomy before bridging & 0 & $7(17.9 \%)$ & $17(24.3 \%)$ & .161 \\
\hline Median $\mathrm{PCO}_{2}$ before bridging (IQR, min-max) & $92(36-136,30-180)$ & $80(61-136,27-177)$ & $90(71-115,29-176)$ & .753 \\
\hline Median $\mathrm{Po}_{2} / \mathrm{FIO}_{2}$ ratio before bridging (IQR, min-max) & $81(50-225,41-300)$ & $109(66-145,44-407)$ & $109(71-162,40-400)$ & .382 \\
\hline Median $\mathrm{pH}$ before bridging (IQR, min-max) & $7.1(6.9-7.1,6.9-7.2)$ & $7.3(7.1-7.4,6.9-7.6)$ & $7.3(7.2-7.4,6.9-7.5)$ & .818 \\
\hline Weaning from mechanical ventilation & 0 & $4(12.1 \%)$ & $11(15.7 \%)$ & .177 \\
\hline \multicolumn{5}{|l|}{ Outcomes } \\
\hline Death during bridging & 0 & $6(15.4 \%)$ & $7(10 \%)$ & \multirow[t]{3}{*}{.002} \\
\hline In-hospital death & $7(63.6 \%)$ & $12(30.8 \%)$ & $9(12.9 \%)$ & \\
\hline Discharge from hospital & $4(36.4 \%)$ & $21(53.8 \%)$ & $54(77.1 \%)$ & \\
\hline \multicolumn{5}{|l|}{ Awake status } \\
\hline Deeply sedated & $11(100 \%)$ & $30(76.9 \%)$ & $46(65.7 \%)$ & \multirow[t]{2}{*}{.043} \\
\hline Awake & 0 & $9(23.1 \%)$ & $24(34.3 \%)$ & \\
\hline \multicolumn{5}{|l|}{ Bridging modalities } \\
\hline VV single-site ECMO & 0 & $4(10.3 \%)$ & $6(8.6 \%)$ & \multirow[t]{7}{*}{.001} \\
\hline VV double-site ECMO & $1(9.1 \%)$ & $13(33.3 \%)$ & $17(24.3 \%)$ & \\
\hline VA & $10(90.9 \%)$ & $14(35.9 \%)$ & $12(17.1 \%)$ & \\
\hline iLA & 0 & $3(7.7 \%)$ & $6(8.6 \%)$ & \\
\hline iLA-ActiVVe & 0 & $1(2.6 \%)$ & $16(22.9 \%)$ & \\
\hline V-AV ECMO & 0 & 0 & $1(1.4 \%)$ & \\
\hline Combination of different modalities & 0 & $4(10.3 \%)$ & $12(17.1 \%)$ & \\
\hline Median length of ECLS bridging (d) (IQR, min-max) & $2(1-3,1-4)$ & $6(3-14,1-63)$ & $5(3-8,1-80)$ & $<.001$ \\
\hline Need for hemofiltration during bridging & $1(9.1 \%)$ & $7(17.9 \%)$ & $12(19 \%)$ & .718 \\
\hline \multicolumn{5}{|l|}{ Type of transplantation } \\
\hline Single & $4(36.4 \%)$ & 0 & $2(3.2 \%)$ & $<.001$ \\
\hline Bilateral & & & & \\
\hline
\end{tabular}


TABLE 1. Continued

\begin{tabular}{|c|c|c|c|c|}
\hline & $\begin{array}{c}1998-2004 \\
(n=11)\end{array}$ & $\begin{array}{c}2005-2010 \\
(n=39)\end{array}$ & $\begin{array}{c}2010-2017 \\
(\mathbf{n}=70)\end{array}$ & $\begin{array}{c}\text { Inter-era } \\
\text { comparison } P \text { value }\end{array}$ \\
\hline Whole organ & $1(9.1 \%)$ & $9(27.3 \%)$ & $30(47.6 \%)$ & \\
\hline Lobar & $4(36.4 \%)$ & $17(51.5 \%)$ & $11(17.5 \%)$ & \\
\hline Size reduced & $1(9.1 \%)$ & $6(18.2 \%)$ & $20(31.7 \%)$ & \\
\hline Split & $1(9.1 \%)$ & $1(3 \%)$ & 0 & \\
\hline \multicolumn{5}{|l|}{ Intraoperative support } \\
\hline Switch of device and cannulation & $2(18.2 \%)$ & $17(51.5 \%)$ & $54(85.7 \%)$ & $<.001$ \\
\hline To central VA-ECMO & $1(9.1 \%)$ & $16(48.5 \%)$ & $51(81 \%)$ & \\
\hline To peripheral VA-ECMO & $1(9.1 \%)$ & $1(3 \%)$ & $3(4.8 \%)$ & \\
\hline On existing device and cannulation & $8(72.7 \%)$ & $15(45.5 \%)$ & $9(14.3 \%)$ & \\
\hline VV & 0 & $5(15.2 \%)$ & 0 & \\
\hline VA & $8(72.7 \%)$ & $10(30.3 \%)$ & $8(12.7 \%)$ & \\
\hline iLA & 0 & 0 & $1(1.6 \%)$ & \\
\hline $\mathrm{CPB}$ & $1(9.1 \%)$ & $1(3 \%)$ & 0 & \\
\hline Prolonged postoperative ECMO & $10(90.9 \%)$ & $24(72.7 \%)$ & $28(44.4 \%)$ & .002 \\
\hline Time on MV (d) (IQR, min-max) & $45(21-52,15-54)$ & $20(8-31,1-180)$ & $9(3-17,1-183)$ & .001 \\
\hline Post-transplant tracheostomy & $11(100 \%)$ & $20(60.6 \%)$ & $29(46 \%)$ & .111 \\
\hline Median ICU stay (d) (IQR, min-max) & $52(27-54,24-55)$ & $32(23-41,8-180)$ & $24(14-37,5-211)$ & .048 \\
\hline Median hospital stay (d) (IQR, min-max) & $70(46-89,43-106)$ & $49(41-64,8-180)$ & $39(27-58,11-234)$ & .018 \\
\hline
\end{tabular}

Bold indicates statistical significance. $I Q R$, Interquartile range; $C O P D$, chronic obstructive pulmonary disease; $C F$, cystic fibrosis; $P P H$, portopulmonary hypertension; $A R D S$, acute respiratory distress syndrome; $C L A D$, chronic lung allograft dysfunction; $P O F$, primary organ failure; $L T x$, lung transplantation; $R e T x$, retransplantation; $P \mathrm{CO}_{2}$, carbon dioxide tension; $\mathrm{PO}_{2}$, oxygen tension; $\mathrm{FIO}_{2}$, inspired oxygen fraction; $V V$, venovenous; $E C M O$, extracorporeal membrane oxygenation; $V A$, venoarterial; $i L A$, interventional lung assist; $V-A V$, veno-arteriovenous; $E C L S$, extracorporeal life support; $C P B$, cardiopulmonary bypass; $M V$, mitral valve; $I C U$, intensive care unit.

bridge patients with primary graft failure to acute retransplantation. The third era was characterized by the use of single-cannula VV ECMO to bridge patients awake. Curves for survival were generated using the Kaplan-Meier method and compared by log-rank tests. The 90-day and 1-year survivals were chosen to report short-term results, whereas 5- and 10-year survivals were used to report long-term survival. To compare survival outcomes of the ECLS-bridged cohort with standard transplant recipients, a semisaturated propensity score matching was applied. A propensity score was assigned to each patient using a logistic regression model with the R-package "Matching." Model selection was performed by stepwise regression and included the following covariates: underlying disease, year of lung transplantation, age, colonization with multiresistant bacteria, size-reduced lung transplantation, bridging goal, pretransplant colonization with Aspergillus, gender, cytomegalovirus risk, pretransplant kidney insufficiency, and pulmonary hypertension. Patients bridged to acute retransplantation or patients who died during bridging were excluded. Matching was performed on the basis of a 1-to-4 nearest neighbor approach without replacement. Weights were chosen to be equal to the inverse of the variance and were used with the default settings provided by the R-package. The caliper was set at 0.02 . The standardized mean differences were computed with the R-package "tableone." In case of categorical variables with multiple levels, the "CreateTableOne" function uses a generalization of the concept of standardized mean differences using the Mahalanobis distance. Inverse histogram plots were used to illustrate the distribution of matched and unmatched patients in the 2 groups (Figures E1 and E2). Detailed demographics of the 2 propensity-matched groups and their actual standardized mean differences are presented in Tables E2 and E3. Univariate and multivariate Cox regression were calculated to determine risk factors for mortality. Variables were included in the multivariable Cox regression when they showed a significant associations in univariate analysis (bridging goal, awake status, and era) or according to clinical plausibility (age). Data were analyzed using SPSS version 24.0 software (SPSS Inc, Chicago, Ill) or R 3.4.2, and graphics were designed with GraphPad Prism 6 (GraphPad Software, San Diego, Calif). This study was approved by the institutional review board of the Medical University of Vienna (EKNr. 1836/2018).

\section{RESULTS \\ Inter-Era Analysis}

A total of 1804 patients underwent transplantation at our institution between January 1998 and December 2017. Of these, an ECLS device was implanted in 120 patients with the intent to bridge to primary lung transplantation $(\mathrm{n}=96)$ or retransplantation $(\mathrm{n}=24)$. The number of bridged patients increased over time, with 11 patients $(9.2 \%)$ in the first era (1998-2004), 39 patients $(32.5 \%)$ in the second era (2005-2010), and 70 patients $(58.3 \%)$ in the third era (2011-2017). Waiting list mortality decreased from $8.2 \%(\mathrm{n}=50 / 610)$ in the first era to $6.9 \%(\mathrm{n}=50 /$ $728)$ in the second era and $3.6 \%(n=32 / 901)$ in the third era. Detailed demographics of the ECLS-bridged cohort are depicted in Table 1, and a comparison of bridged and nonbridged patients is depicted in Table E4. In the first era, most patients $(\mathrm{n}=8,72.7 \%)$ were bridged to acute retransplantation because of primary organ failure. In the second and third eras, cystic fibrosis, pulmonary fibrosis, and chronic lung allograft dysfunction were the 3 main diagnoses. Ventilation strategy during ECLS bridging changed significantly over time. In the early days, all patients were sedated and kept on mechanical ventilation during bridging. In the most recent era, $15.7 \%$ of patients (11/70) could be weaned completely from mechanical ventilation after 
ECLS initiation. More patients could be bridged awake in the last era $(\mathrm{n}=24,34.3 \%)$ compared with the first 2 eras $(P=.043)$. Awake patients performed active physiotherapy in bed and were sat up once or twice daily. A small proportion of patients were also able to ambulate.

Single lung transplantation was performed in 4 patients $(36 \%)$ in the early time period but did not play a role thereafter. A high percentage of lobar transplantations in all 3 eras underlines the necessity to accept donors with imperfect size matching in this urgent patient population. However, lobar transplantation declined over time because of the increasingly used strategy of extra-anatomic downsizing $(9.1 \%$ in the first era, $18.2 \%$ in the second era, and $31.7 \%$ in the third era; $P<.001)$. In the early days of our experience, most patients underwent transplantation using the existing ECLS device for intraoperative support (72.7\% in the first era, $45.5 \%$ in the second era, and $14.3 \%$ in the third era; $P<.001$ ). This strategy has gradually changed, and a switch to central VA-ECMO became more common: $18 \%$ in the first era, $52 \%$ in the second era, and $86 \%$ in the third era $(P<.001)$. ECMO was prolonged into the early postoperative period with the following frequencies: $91 \%$ in the first era, $73 \%$ in the second era, and $44 \%$ in the third era $(P=.003)$.

In the early time period, VA ECMO was the preferentially used bridging device $(91 \%)$. This changed over time, with ECCO2-R (23\% iLA ActiVVe) and VVECMO $(33 \%)$ being the most frequently used devices after $2010(P=.001)$. In 16 patients, the initial ECLS modality was changed during the bridging period. Downgrading was possible in only 3 patients, whereas upgrading was necessary in 13 patients. Three patients required an upgrade from ECCO2-R to VV-ECMO because of hypoxemia. All 3 patients underwent transplantation. Eight patients required a switch from ECCO2-R/VV-ECMO to a VAECMO because of hemodynamic deterioration; 3 of them died before transplantation. Finally, 2 patients initially bridged with PA/LA-Novalung required a switch to a conventional VA-ECMO. The first patient developed biventricular failure with concomitant clotting of the membrane; thus, the drainage and injection cannulas were directly connected to an ECMO circuit and a peripheral VA ECMO was inserted. In the other case, the LA injection cannula dislocated, and the patient was switched to conventional femoro-femoral VA-ECMO during the revision for hemothorax.

\section{Complications}

In 4 patients, a vessel injury was reported during percutaneous cannulation, which led to a consecutive hemothorax (2 jugular sites, 2 subclavian sites) (Figure E3). As mentioned above, in 1 case of PA/LA Novalung, cannulas dislocated, requiring revision. In addition, ECLS cannulas had to be changed because of clotting in 7 cases. Technical failure of

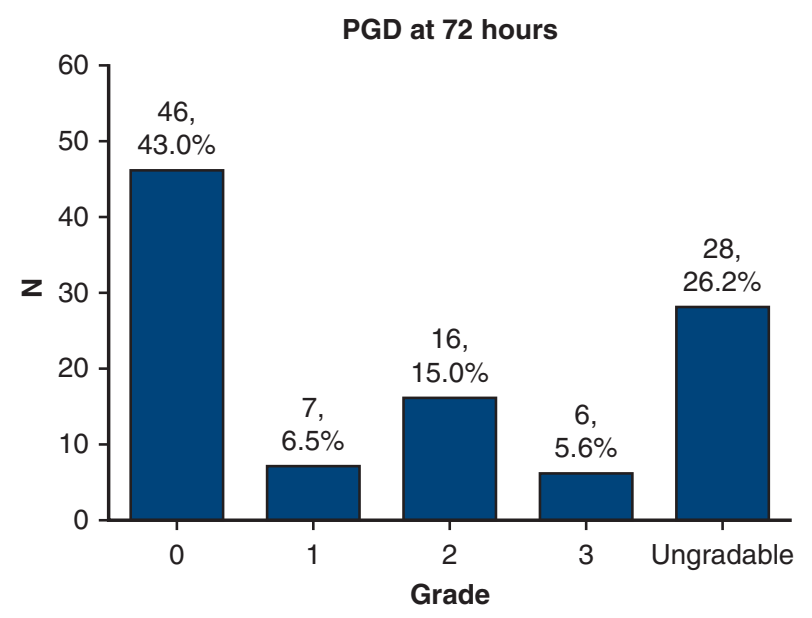

FIGURE 1. PGD grade of ECLS-bridged patients at 72 hours. Forty-six patients $(43.0 \%)$ were graded as PGD0, 7 patients $(6.5 \%)$ were graded as PGD1, 16 patients $(15.0 \%)$ were graded as PGD2, 6 patients $(5.6 \%)$ were graded as PGD3, and 28 patients $(26.2 \%)$ were classified as ungradable. $P G D$, Primary graft dysfunction.

ECLS components was reported in 2 patients. Both cases resolved after changing the system without detrimental consequences. One patient had disseminated intravascular coagulation after cardiopulmonary resuscitation on femorosubclavian VA-ECMO. The patient underwent transplantation and is still alive 6 years after the procedure. A detailed list of complications after transplantation is depicted in Figure E4. Thirty-five patients $(33 \%)$ experienced a hemothorax after lung transplantation, and 45 patients $(42 \%)$ needed a temporary renal replacement therapy. None of them developed a permanent kidney failure. In 27 patients, transient neurologic impairments were reported (postoperative organic syndrome, posterior reversible encephalopathy syndrome, and polyneuropathy). One of our patients experienced a cerebral embolism after transplantation.

\section{Outcome Analysis}

Eighty-nine percent $(n=107)$ of ECLS-bridged patients reached transplantation. For these patients, post-transplant median time on mechanical ventilation, median length of intensive care unit stay, and median hospital stay decreased gradually over time (Table 1). Primary organ function at 72 hours is depicted in Figure 1. Only 6 (5.6\%) ELCSbridged patients were classified as PGD3. However, in 28 patients $(26.2 \%)$, ECMO was prolonged for prophylactic purposes into the early postoperative period according to our institutional protocol, ${ }^{14}$ and PGD was classified as "ungradable." Patients bridged in the first era had the highest rate of in-hospital mortality (64\%), which decreased to $31 \%$ in the second era and to $13 \%$ in the third era $(P=.002)$. Survival at 90 days, 1 year, 5 years, and 10 years significantly improved over time (Figure 2 and Table 2). Ninety-day and 1-year survival of ECLS-bridged patients 


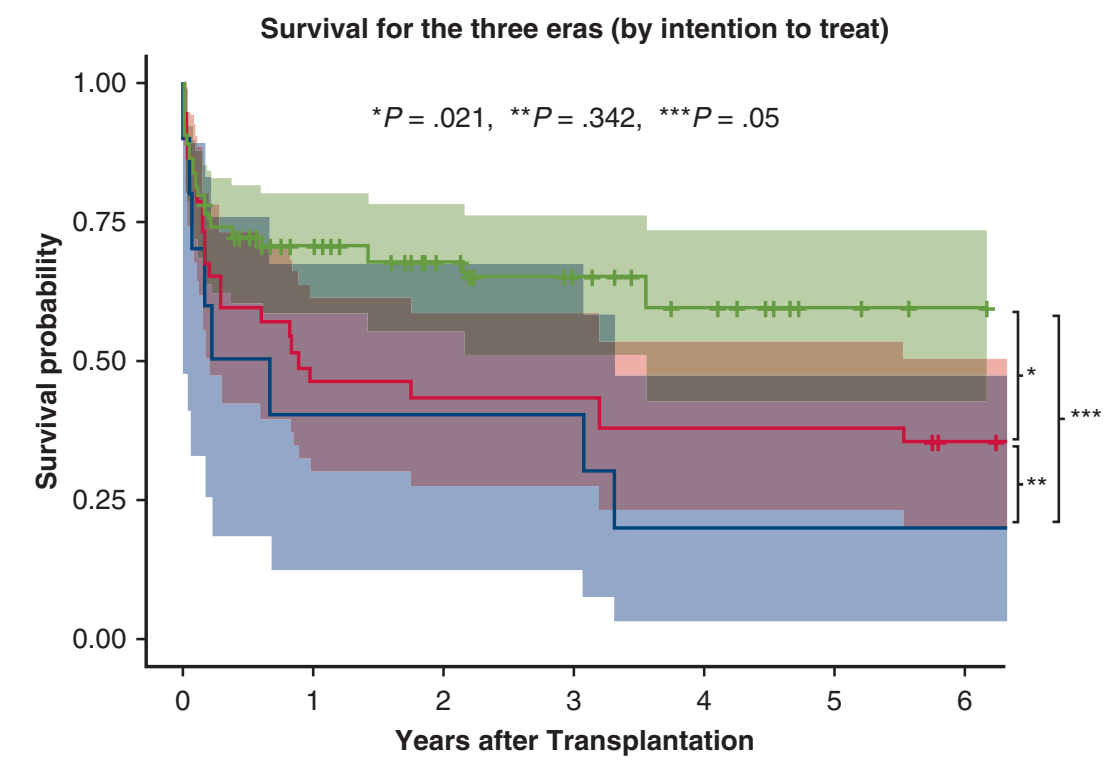

\begin{tabular}{|c|c|c|c|c|c|c|c|}
\hline \multicolumn{8}{|c|}{ Number at risk } \\
\hline First era & 10 & 4 & 4 & 4 & 2 & 2 & 2 \\
\hline Second era & 37 & 17 & 16 & 16 & 14 & 14 & 11 \\
\hline Third era - & 69 & 33 & 23 & 15 & 10 & 3 & 1 \\
\hline
\end{tabular}

FIGURE 2. Kaplan-Meier survival curves calculated as by intention to treat for each era. A constant improvement in outcome as by intention to treat was observed during the study period. Survivals at 90 days, 1 year, 5 years, and 10 years are $55 \%, 44 \%, 22 \%$, and $22 \%$ for the first era, respectively, $73 \%, 51 \%$, $42 \%$, and, $39 \%$ for the second era, respectively, and $85 \%, 77 \%$ and $65 \%$ for the third era, respectively (first vs second era $P=.021$, second vs third era $P=.160$, and first vs third era $P=.001)$.

were lower compared with nonbridged patients stratified by propensity score matching $(80 \%$ and $69 \%$ vs $92 \%$ and $86 \% ; P<.001$ ) (Figure 3). The same was found for 5 and 10 -year survival rates: $77 \%$ and $70 \%$ for the control cohort and $60 \%$ and $57 \%$ for ECLS bridged patients, respectively $(P<.001)$ (Figure 3$)$. To assess the postrecovery phase, a landmark analysis conditional on 90-day survival was performed. Long-term survival remained slightly impaired in the bridged patient cohort, although this observation did not reach significance any longer ( $84 \%$ and $71 \%$ control group, $74 \%$ and $72 \%$ for the bridging cohort; $P=.178$ ) (Figure 4). Detailed data on causes of death are shown in Table E5. In total, 59 patients died within the study period. Thirteen patients $(10.8 \%)$ died during the bridging period, 28 patients $(23.3 \%)$ died in the early postoperative period, and 18 patients $(15 \%)$ died during long-term follow-up.

Finally, we compared the characteristics of patients reaching transplantation with those who died during the bridging period (Table E6). Patients who died during bridging were more likely to be sedated and mechanically ventilated. In addition, they had a longer ECLS bridging time. In a next step, univariate and multivariate analysis were performed to find predictors of survival (Tables E7 and E8). In univariate analysis, an awake status (hazard ratio, $0.381,0.186-0.779, P=.008$ ) was protective for survival, whereas bridging to acute retransplantation (hazard ratio, 2.856, 1.206-6.767, $P=.017$ ) was a strong risk factor for mortality. Both variables remained independent factors of survival in a multivariate analysis.

\section{DISCUSSION}

The first reported use of ECLS in deteriorating lung transplantation candidates dates back as far as $1975 .{ }^{7}$ However, the concept was not broadly implemented before the 2000s. Overlooking 20 years of ECLS bridging at our institution, we aimed to summarize our experience, describe the main trends over time, and define predictors for survival (Video 1). We found a significant era effect with shortand long-term outcomes of bridged patients being fairly comparable to standard recipients in the most recent time.

Although ECLS bridging is an increasingly used strategy, few single-center reports exist. After initial case reports, the first 2 relevant series were published in $2011 .^{15,16}$ These series included 16 and 17 patients with 1-year survival of $92 \%$ and $76 \%$ after transplantation, respectively. In both studies, the preferred ECLS modalities were 2-site VV and VA-ECMOs. Shortly thereafter, other institutions 
TABLE 2. Patient survival in different eras

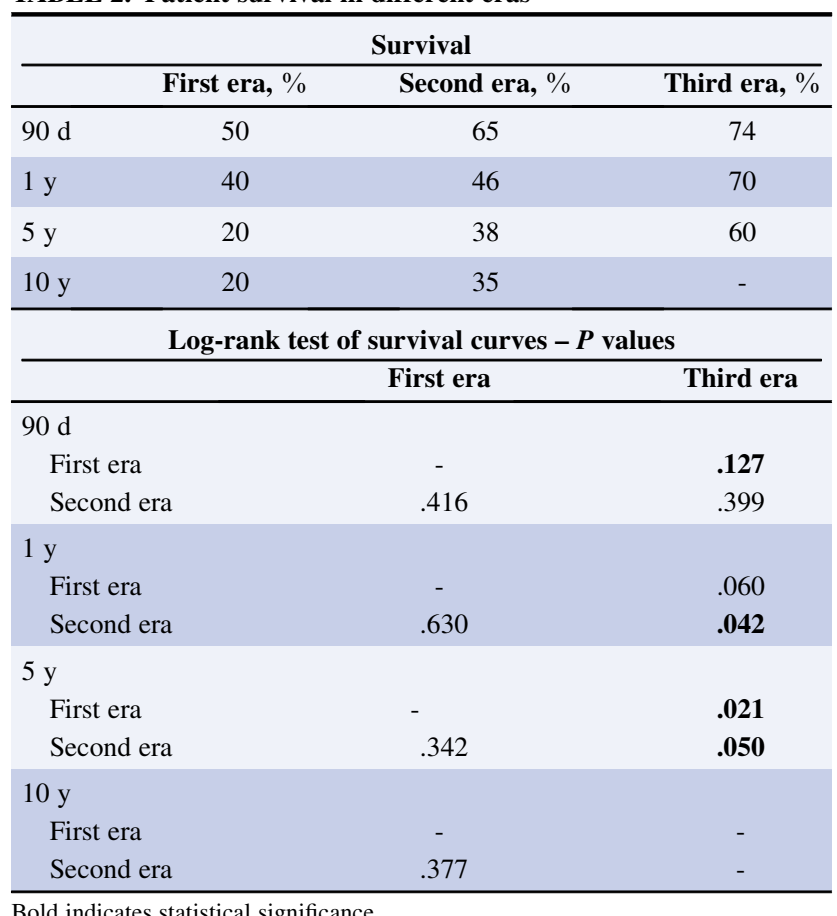

Bold indicates statistical significance.

reported their experience with $68 \%$ to $90 \%$ of ECLSbridged patients reaching transplantation and 1-year survival of $60 \%$ to $93 \% .^{11,17-22}$ Our group published the first larger series of 38 patients bridged to primary transplantation with ECLS in 2012. ${ }^{11}$ Although early survival after lung transplantation was lower for bridged patients compared with standard recipients, encouraging 3 - and 5-year survivals of $60 \%$ and $48 \%$ were found. To date, only 2 studies with more than 70 patients have been published. The Columbia group reported excellent outcomes, with $90 \%$ of patients being alive 1 year after lung transplantation. ${ }^{23}$ This group followed a strict selection of transplant candidates and a high percentage of bridging patients were delisted mainly because of the inability to ambulate for more than 5 consecutive days, multiorgan dysfunction, and sepsis from a multidrug-resistant pathogen. The Toronto group has recently reported good survival in their ECLS-bridged patients, with $89 \%$ of patients reaching transplantation. ${ }^{24}$

The concept of using ECLS devices for bridging has opened a whole new field of therapeutic possibilities. First, ECLS can rescue patients who fail to stabilize despite intubation and high ventilatory effort. Failure of mechanical ventilation is frequently observed in patients with endstage cystic fibrosis with infectious exacerbations and in patients with fibrosis. ${ }^{4-6}$ Modern VV ECMO devices can fully replace a patient's respiratory function and in most cases even facilitate extubation after a phase of stabilization. Second, ECLS can be used in deteriorating patients instead of mechanical ventilation. With the development of new devices and cannulas and improvement of technical skills, we and others started to insert ECLS devices in awake patients under local anesthesia. In the majority of cases, these patients do not require intubation and can be bridged to transplantation in a mobilized way. Currently, no general rules exist regarding the ideal time of ECLS initiation. We have recently implemented institutional guidelines that patients with increasing $\mathrm{PCO}_{2}$ $(>70 \mathrm{~mm} \mathrm{Hg}$ ) in arterial blood despite continuous positive airway pressure therapy are candidates for initiation of awake ECLS implementation.

By looking at the literature, it is currently unclear whether ECLS is a better bridging strategy compared with mechanical ventilation. In a United Network for Organ Sharing database analysis, Mason and colleagues ${ }^{25}$ found comparable outcomes in patients bridged with mechanical ventilation and ECLS. This finding was confirmed by George and colleagues, ${ }^{26}$ who reported similar survival for patients bridged with ECMO compared with mechanical ventilation. However, this group further reported that outcomes after ECMO bridging significantly improved over time. Most recently, the Pittsburgh group updated their bridging experience and found that the addition of ECMO in patients bridged with mechanical ventilation resulted in improved survival. Most of these analyses are hampered by a retrospective study design and significant differences in patient characteristics between the study groups. Despite this lack of data, ECLS is currently considered superior to mechanical ventilation as a long-term bridging concept.

The current study highlights the evolution of ECLS bridging over 20 years, with significantly improved outcomes over time. This improvement has several reasons. First, we observed a marked learning curve with the increasing use of ECLS at our center. Complications associated with cannulation technique and coagulation management mainly occurred in the early eras but significantly decreased with standardization of our protocols. Furthermore, we have become more selective when choosing patients eligible for ECLS bridging. As an example, the bridging concept for acute retransplantation was completely abandoned. In addition, technical developments and availability of different devices have led to individualized bridging concepts based on the type of physiologic impairment. A major improvement was the introduction of hollow-fiber, polymethylpentene oxygenators, which allowed for better oxygenation and required less heparinization. Another improvement was the introduction of duallumen cannulas. These cannulas facilitate mobilization and ambulation with blood flow nearly equal to a standard double-site cannulation. Heparin-coated circuits, which are currently routinely used, are associated with a lower rate of hemolysis and inflammation. Finally, lowresistance polymethylpentene membranes (eg, iLA 


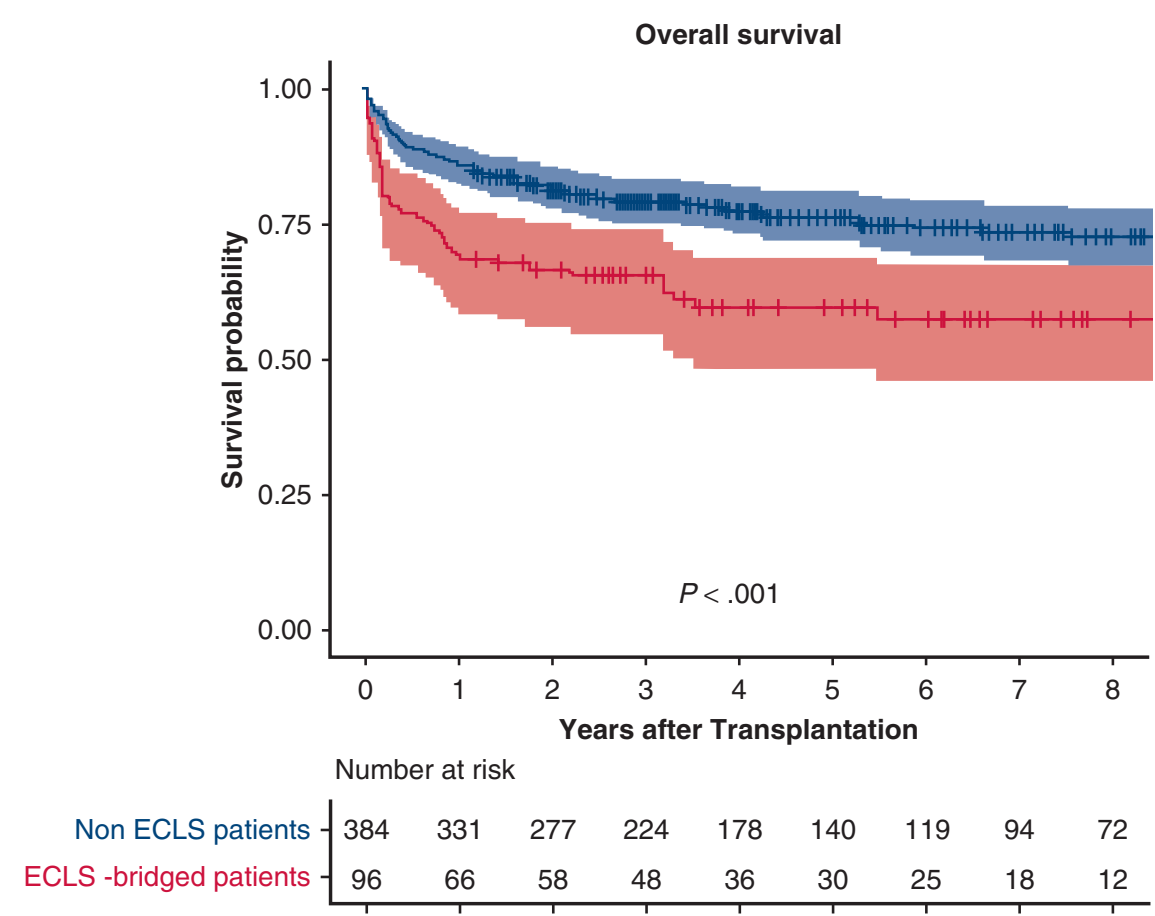

Non ECLS patients

ECLS -bridged patients

FIGURE 3. Overall survival of ECLS-bridged patients versus nonbridged patients after propensity score matching. Survival was significantly better in the nonbridged group, mainly due to a favorable early postoperative outcome $(P<.001)$. ECLS, Extracorporeal life support.

membrane) complete the ECLS armamentarium. These membranes allow gas exchange by simple diffusion and are the basis of modern ECCO2-R strategies. The long time period of ECLS bridging at our institution allowed us to assess era effects and differences in clinical practice and outcomes over time. In the first era, patients were exclusively bridged deeply sedated and intubated. Furthermore, ECLS was mainly used as a bridge to acute retransplantation with poor results. Impaired outcomes of acute retransplantation has also been shown by other groups, ${ }^{27-29}$ and this practice was abandoned in most centers. The second and third eras were characterized by the transition from VA ECMO to less invasive VV support with the implementation of an awake, ambulatory ECLS concept. After 2010, the percentage of awake patients increased, and devices such as iLA-ActiVVe became an important part of our clinical practice. This transition toward lessinvasive ECLS devices has also been reported by other lung transplantation centers. ${ }^{19-22,30,31}$ Fuehner and colleagues ${ }^{17}$ found improved survival and shorter postoperative length of mechanical ventilation in patients bridged awake compared with a historical group of sedated patients. Nosotti and colleagues ${ }^{31}$ found similar results in their patient cohort, and Hoopes and colleagues ${ }^{18}$ reported excellent survival in 26 ECLS bridged patients, 18 of them in ambulatory status. Our own institution reported on a series of 20 patients bridged by ECCO2-R with excellent results, with many of these patients bridged in an ambulatory state. ${ }^{32}$ Only recently, Schechter and colleagues ${ }^{33}$ published the first United Network for Organ Sharing database analysis, focusing on awake ECLS bridging. In a cohort of approximately 12,500 lung transplantation recipients, 65 $(0.52 \%)$ were bridged with ECMO in an awake, spontaneously breathing setting and $119(0.96 \%)$ required mechanical ventilation during ECMO bridging. Outcome was significantly better in the former group with a 3 -year survival of $64.5 \%$.

There is currently no consensus in the literature on how to proceed when patients deteriorate during ECLS bridging. In the Columbia cohort, patients who failed to perform physiotherapy for more than 5 days, septic patients, and patients requiring renal replacement therapy were delisted until they clinically improved. ${ }^{23}$ With this conservative strategy, only $56 \%$ of patients reached transplantation; however, their post-transplant outcome was excellent. Most other transplant units, including Toronto, Hannover, and our institution, follow a different concept. In our patient cohort, hemodynamic compromise in VV-bridged patients was addressed by an upgrade to VA devices and renal replacement therapy was not considered a contraindication for lung transplantation. In fact, hemofiltration was used liberally to maintain fluid balance. Of note, kidney dysfunction 


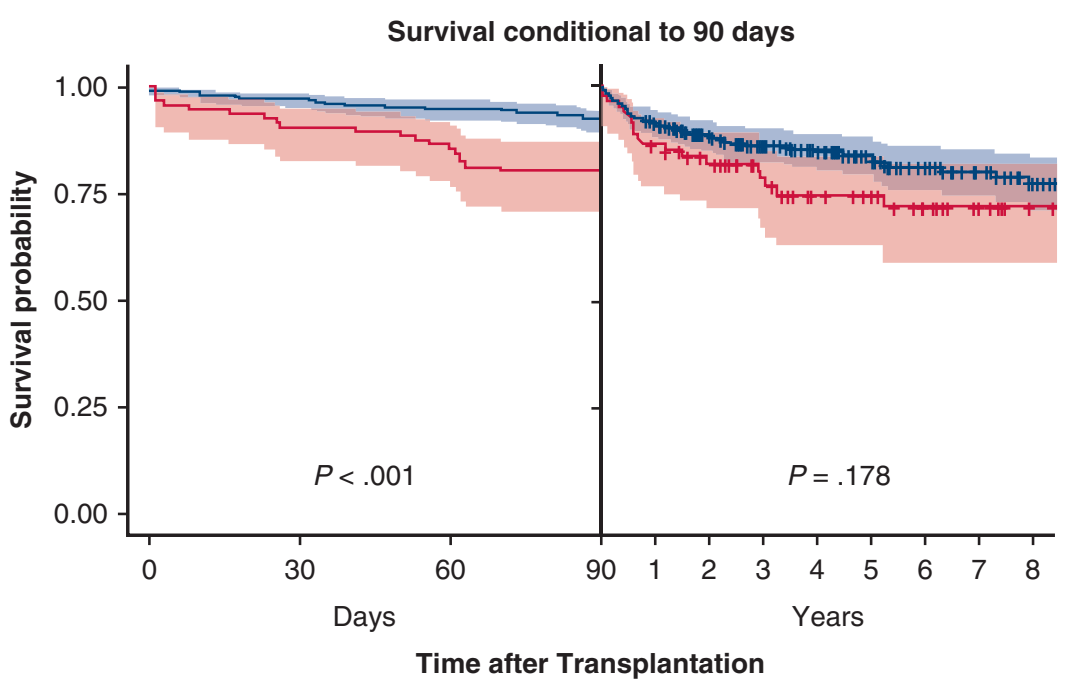

Number at risk
Non ECLS patients
ECLS -bridged patients

FIGURE 4. Survival conditional to survival at 90 days after propensity matching ECLS-bridged patients and nonbridged patients. After adjusting for the perioperative mortality, long-term survival was comparable between the groups $(P=.178)$. The 5 - and 10 -year survivals were $84 \%$ and $71 \%$ for the control group and $74 \%$ and $72 \%$ for the bridging cohort, respectively. ECLS, Extracorporeal life support.

was completely reversible in all patients after transplantation. Moreover, inability to ambulate was not a reason for transplant ineligibility. Although ambulatory awake ECMO was associated with better outcomes, in this very sick patient cohort, ambulation was not always possible. Over the reported 20 years, $89 \%$ of our patients reached transplantation, with only 3 patients being removed from the waiting list because of severe sepsis and multiorgan failure. This strategy of proceeding to transplantation, whenever possible, comes with the cost of a higher perioperative mortality. However, given that the alternative

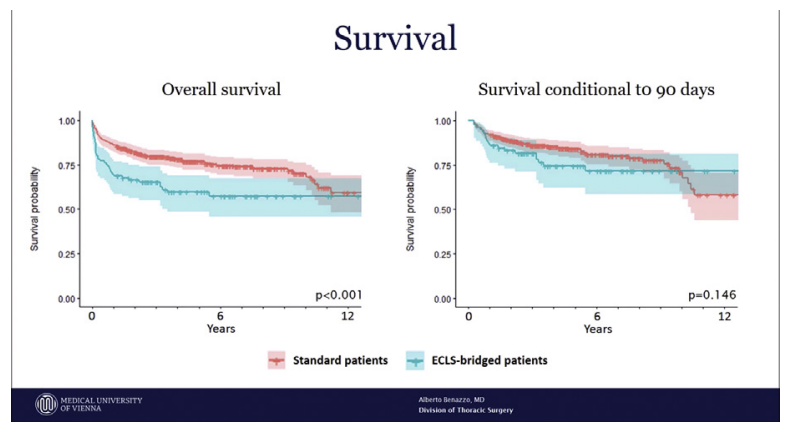

VIDEO 1. Summary of the main features of the 20-year ECLS bridging experience in our institution. Video available at: https://www.jtcvs.org/ article/S0022-5223(19)30488-X/fulltext. to transplantation is certain death $(100 \%$ mortality without a transplant), the reported 1-year survival of $70 \%$ in the last era seems appealing. Donor organs are a scarce resource, and the use of organs for such a sick population requires rigorous justification and transparent outcome reporting. To date, these ethical concerns and distribution justice of donor organs in the era of ECLS bridging have not been broadly discussed.

The reported PGD grades in this study require a closer look. A high number of patients remained on extracorporeal support after transplantation. On the basis of our institutional strategy, we liberally prolong ECMO into the early postoperative period whenever the newly implanted lungs fail to meet certain quality criteria in the operating room. ${ }^{14}$ The decision to use ECMO in this prophylactic way is made before structural impairment, consistent with severe reperfusion edema, becomes evident. According to the latest International Society for Heart and Lung Transplantation consensus, such prophylactic ECMO strategies should be considered when reporting PGD grades, and patients should be classified as "ungradable." In our cohort, severe PGD was only reported in $5 \%$ of patients.

Bridged patients are at a higher risk for postoperative frailty, ventilation-dependent injuries, ECLS-related complications, and kidney failure. However, if this challenging perioperative phase is conquered, survival only slightly differs from survival of nonbridged patients 
(Figure 4). Early referral and careful selection of bridging candidates, clear definition of criteria for transplant eligibility, and improvement of preoperative muscular status by intensive physiotherapy are measures that may further reduce perioperative risks. The duration of ECLS bridging is also an important prognostic factor. Although bridging periods of up to 3 months have been described in the literature, the likelihood of adverse events (ie, bleeding, thromboembolic events) increases over time. In our patient cohort, median bridging time was only 5 days, which is significantly shorter compared with bridging times reported in the United States and Canada. The reason for this is probably the pronounced organ sharing within Eurotransplant. Patients on ECLS device are prioritized and can usually undergo transplantation within a few days.

\section{Study Limitations}

One of the main limitations of this study is its retrospective nature. Covering a long period of time, documentation was found incomplete in some of the early cases, and details of the perioperative management are missing. Also, treatment protocols and immunosuppressive strategies changed over time. Thus, caution is required in interpreting the data of this study.

\section{CONCLUSIONS}

ECLS bridging has evolved over the last 2 decades from an acute rescue therapy to a semi-elective procedure. ECLS is currently a safe and successful tool to bridge deteriorating patients to lung transplantation with acceptable long-term outcomes.

\section{Conflict of Interest Statement}

Authors have nothing to disclose with regard to commercial support.

\section{References}

1. Levine S, Nguyen T, Taylor N, Friscia ME, Budak MT, Rothenberg P, et al. Rapid disuse atrophy of diaphragm fibers in mechanically ventilated humans. $N$ Engl J Med. 2008;358:1327-35.

2. Schweickert WD, Hall J. ICU-acquired weakness. Chest. 2007;131:1541-9.

3. Chastre J, Fagon JY. Ventilator-associated pneumonia. Am J Respir Crit Care Med. 2002;165:867-903.

4. Singer JP, Blanc PD, Hoopes C, Golden JA, Koff JL, Leard LE, et al. The impact of pretransplant mechanical ventilation on short- and long-term survival after lung transplantation. Am J Transplant. 2011;11:2197-204.

5. O'Brien G, Criner GJ. Mechanical ventilation as a bridge to lung transplantation. J Heart Lung Transplant. 1999;18:255-65.

6. Elizur A, Sweet SC, Huddleston CB, Gandhi SK, Boslaugh SE, Kuklinski CA, et al. Pre-transplant mechanical ventilation increases short-term morbidity and mortality in pediatric patients with cystic fibrosis. J Heart Lung Transplant. 2007;26:127-31.

7. Veith FJ. Lung transplantation. Transplant Proc. 1977;9:203-8.

8. Sequential bilateral lung transplantation for paraquat poisoning. A case report. The Toronto Lung Transplant group. J Thorac Cardiovasc Surg. 1985;89:734-42.

9. Zapol WM, Snider MT, Hill JD, Fallat RJ, Bartlett RH, Edmunds LH, et al. Extracorporeal membrane oxygenation in severe acute respiratory failure. A randomized prospective study. JAMA. 1979;242:2193-6.
10. Hayanga AJ, Aboagye J, Esper S, Shigemura N, Bermudez CA, D’Cunha J, et al. Extracorporeal membrane oxygenation as a bridge to lung transplantation in the United States: an evolving strategy in the management of rapidly advancing pulmonary disease. J Thorac Cardiovasc Surg. 2015;149:291-6.

11. Lang G, Taghavi S, Aigner C, Rényi-Vámos F, Jaksch P, Augustin V, et al. Primary lung transplantation after bridge with extracorporeal membrane oxygenation: a plea for a shift in our paradigms for indications. Transplantation. 2012; 93:729-36.

12. de Perrot M, Granton JT, McRae K, Cypel M, Pierre A, Waddell TK, et al. Impact of extracorporeal life support on outcome in patients with idiopathic pulmonary arterial hypertension awaiting lung transplantation. J Heart Lung Transplant. 2011;30:997-1002.

13. Snell GI, Yusen RD, Weill D, Strueber M, Garrity E, Reed A, et al. Report of the ISHLT Working Group on Primary Lung Graft Dysfunction, part I: Definition and grading-A 2016 Consensus Group statement of the International Society for Heart and Lung Transplantation. J Heart Lung Transplant. 2017;36: $1097-103$.

14. Hoetzenecker K, Schwarz S, Muckenhuber M, Benazzo A, Frommlet F, Schweiger T, et al. Intraoperative ECMO and the possibility of postoperative prolongation improve survival in bilateral lung transplantation. J Thorac Cardiovasc Surg. 2018;155:2193-206.e3.

15. Hämmäinen P, Schersten H, Lemström K, Riise GC, Kukkonen S, Swärd K, et al. Usefulness of extracorporeal membrane oxygenation as a bridge to lung transplantation: a descriptive study. J Heart Lung Transplant. 2011;30:103-7.

16. Bermudez CA, Rocha RV, Zaldonis D, Bhama JK, Crespo MM, Shigemura N, et al. Extracorporeal membrane oxygenation as a bridge to lung transplant: midterm outcomes. Ann Thorac Surg. 2011;92:1226-32.

17. Fuehner T, Kuehn C, Hadem J, Wiesner O, Gottlieb J, Tudorache I, et al. Extracorporeal membrane oxygenation in awake patients as bridge to lung transplantation. Am J Respir Crit Care Med. 2012;185:763-8.

18. Hoopes CW, Kukreja J, Golden J, Davenport DL, Diaz-Guzman E, Zwischenberger JB, et al. Extracorporeal membrane oxygenation as a bridge to pulmonary transplantation. J Thorac Cardiovasc Surg. 2013; $145: 862-8$.

19. Toyoda Y, Bhama JK, Shigemura N, Zaldonis D, Pilewski J, Crespo M, et al. Efficacy of extracorporeal membrane oxygenation as a bridge to lung transplantation. J Thorac Cardiovasc Surg. 2013;145:1065-71.

20. Lafarge M, Mordant P, Thabut G, Brouchet L, Falcoz PE, Haloun A, et al. Experience of extracorporeal membrane oxygenation as a bridge to lung transplantation in France. J Heart Lung Transplant. 2013;32:905-13.

21. Shafii AE, Mason DP, Brown CR, Vakil N, Johnston DR, McCurry KR, et al. Growing experience with extracorporeal membrane oxygenation as a bridge to lung transplantation. ASAIO J. 2012;58:526-9.

22. Crotti S, Iotti GA, Lissoni A, Belliato M, Zanierato M, Chierichetti M, et al. Organ allocation waiting time during extracorporeal bridge to lung transplant affects outcomes. Chest. 2013;144:1018-25.

23. Biscotti M, Gannon WD, Agerstrand C, Abrams D, Sonett J, Brodie D, et al. Awake extracorporeal membrane oxygenation as bridge to lung transplantation: a 9-year experience. Ann Thorac Surg. 2017;104:412-9.

24. Hoetzenecker K, Donahoe L, Yeung JC, Azad S, Fan E, Ferguson ND, et al. Extracorporeal life support as a bridge to lung transplantation-experience of a high-volume transplant center. J Thorac Cardiovasc Surg. 2018;155:1316-28.e1.

25. Mason DP, Thuita L, Nowicki ER, Murthy SC, Pettersson GB, Blackstone EH, et al. Should lung transplantation be performed for patients on mechanical respiratory support? The US experience. J Thorac Cardiovasc Surg. 2010;139: 765-73.e1.

26. George TJ, Beaty CA, Kilic A, Shah PD, Merlo CA, Shah AS, et al. Outcomes and temporal trends among high-risk patients after lung transplantation in the United States. J Heart Lung Transplant. 2012;31:1182-91.

27. Hayanga JW, Aboagye JK, Hayanga HK, Luketich JD, D’Cunha J. Extracorporeal membrane oxygenation as a bridge to lung re-transplantation: is there a role? J Heart Lung Transplant. 2016;35:901-5.

28. Kawut SM, Lederer DJ, Keshavjee S, Wilt JS, Daly T, D'Ovidio F, et al. Outcomes after lung retransplantation in the modern era. Am J Respir Crit Care Med. 2008;177:114-20.

29. Novick RJ, Stitt LW, Al-Kattan K, Klepetko W, Schäfers HJ, Duchatelle JP, et al. Pulmonary retransplantation: predictors of graft function and survival in 230 patients. Pulmonary Retransplant Registry. Ann Thorac Surg. 1998;65:227-34.

30. Javidfar J, Brodie D, Iribarne A, Jurado J, Lavelle M, Brenner K, et al. Extracorporeal membrane oxygenation as a bridge to lung transplantation and recovery. $J$ Thorac Cardiovasc Surg. 2012;144:716-21. 
31. Nosotti M, Rosso L, Tosi D, Palleschi A, Mendogni P, Nataloni IF, et al. Extracorporeal membrane oxygenation with spontaneous breathing as a bridge to lung transplantation. Interact Cardiovasc Thorac Surg. 2013;16: $55-9$.

32. Schellongowski P, Riss K, Staudinger T, Ullrich R, Krenn CG, Sitzwohl C, et al. Extracorporeal $\mathrm{CO} 2$ removal as bridge to lung transplantation in life-threatening hypercapnia. Transpl Int. 2015;28:297-304.
33. Schechter MA, Ganapathi AM, Englum BR, Speicher PJ, Daneshmand MA Davis RD, et al. Spontaneously breathing extracorporeal membrane oxygenation support provides the optimal bridge to lung transplantation. Transplantation. 2016;100:2699-704

Key Words: ECLS, bridging, lung transplantation 


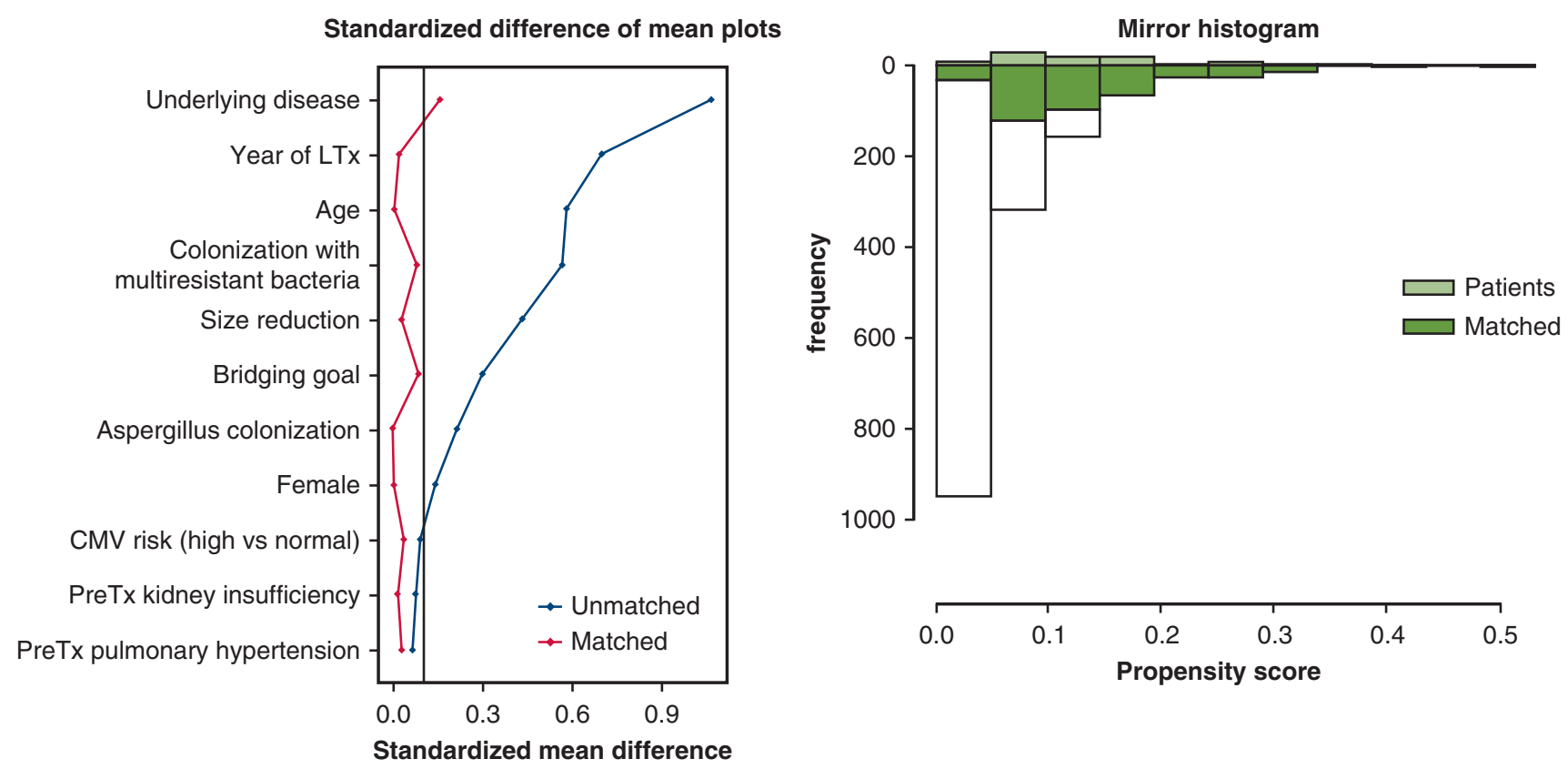

FIGURE E1. Standardized difference of mean plots and mirrored histograms show sufficient stratification of bridged patients and standard recipients before and after propensity score matching. Underlying disease: chronic obstructive pulmonary disease, interstitial lung disease, idiopathic pulmonary hypertension, cystic fibrosis, chronic lung allograft dysfunction, and other less frequent diseases. LTX, Lung transplantation; CMV, cytomegalovirus; PreTx, pretransplant.
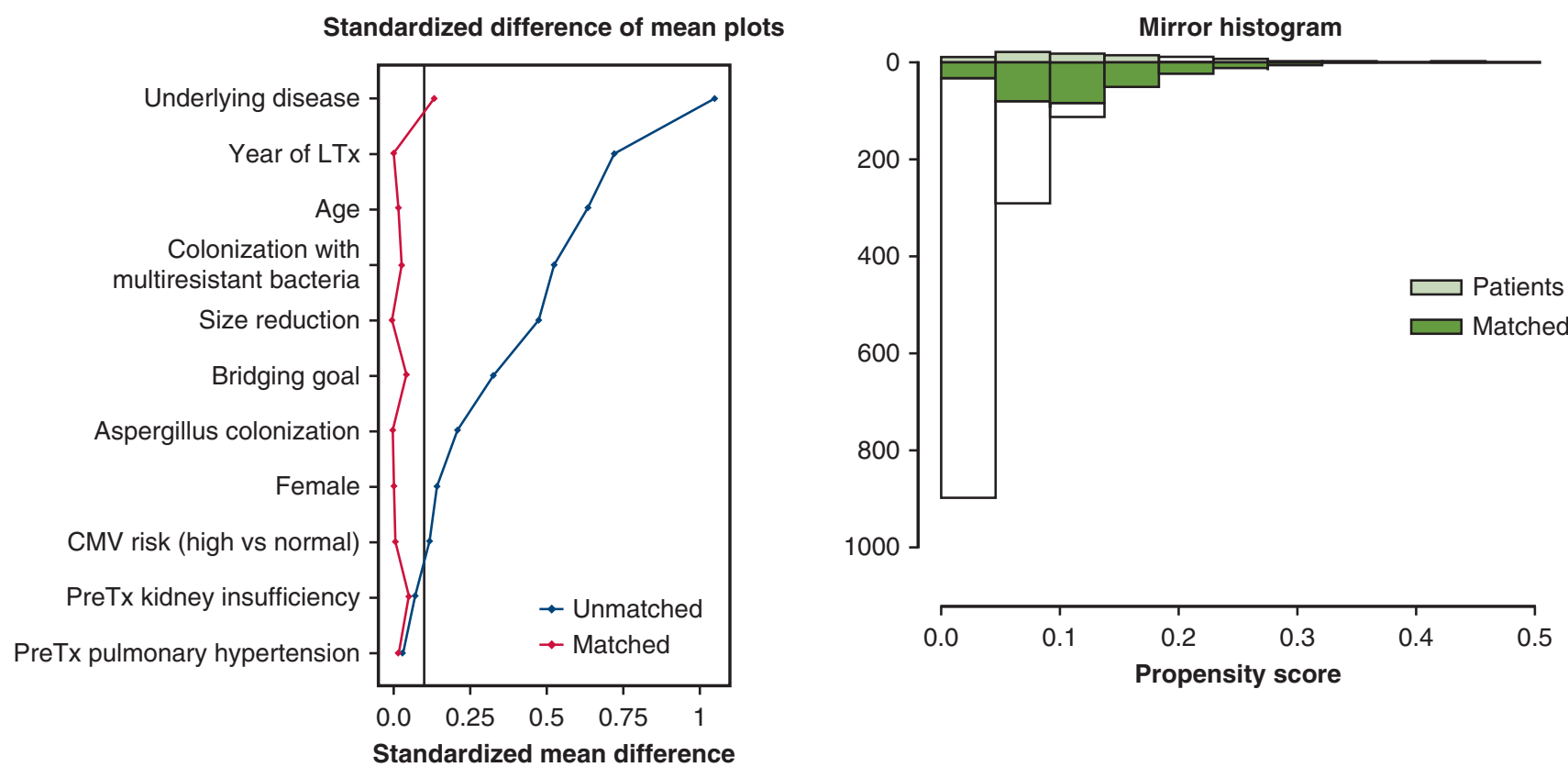

FIGURE E2. Standardized difference of mean plots and mirrored histograms depicting a good grade of stratification of bridged patients and standard recipients conditioned to 90-day survival before and after propensity score matching. Underlying disease: chronic obstructive pulmonary disease, interstitial lung disease, idiopathic pulmonary hypertension, cystic fibrosis, chronic lung allograft dysfunction, and other less frequent diseases. LTx, Lung transplantation; CMV, cytomegalovirus; PreTx, pretransplant. 


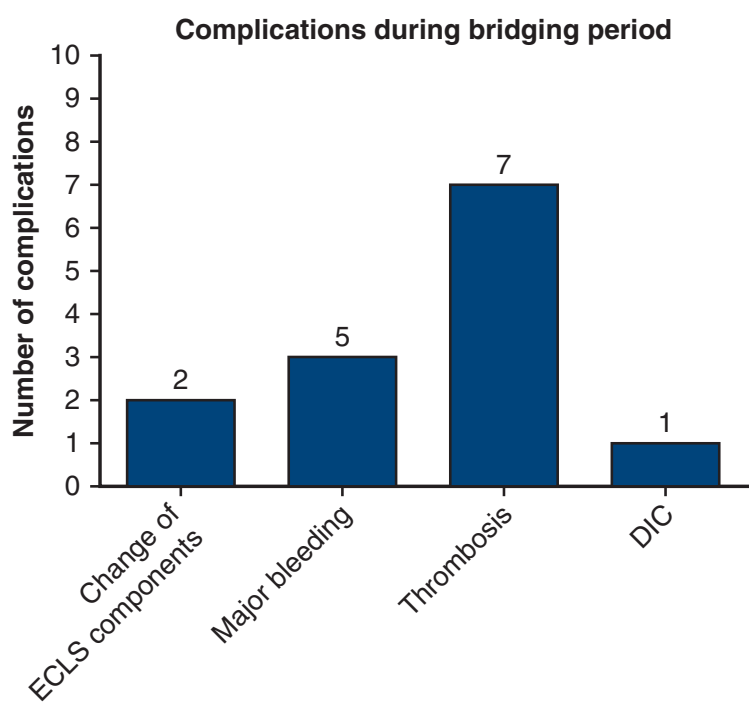

FIGURE E3. Complications during ECLS bridging. In 4 patients, a vessel injury was reported during percutaneous cannulation ( 2 jugular sites, 2 subclavian sites). In 1 case of PA/LA Novalung (Xenios, New York, NY), the venous cannula dislocated. Thrombosis of a cannula was reported in 7 cases. Technical failure of ECLS components was observed in 2 patients. One patient had disseminated intravascular coagulation after cardiopulmonary resuscitation on femoro-subclavian VA-ECMO. ECLS, Extracorporeal life support; DIC, disseminated intravascular coagulopathy.

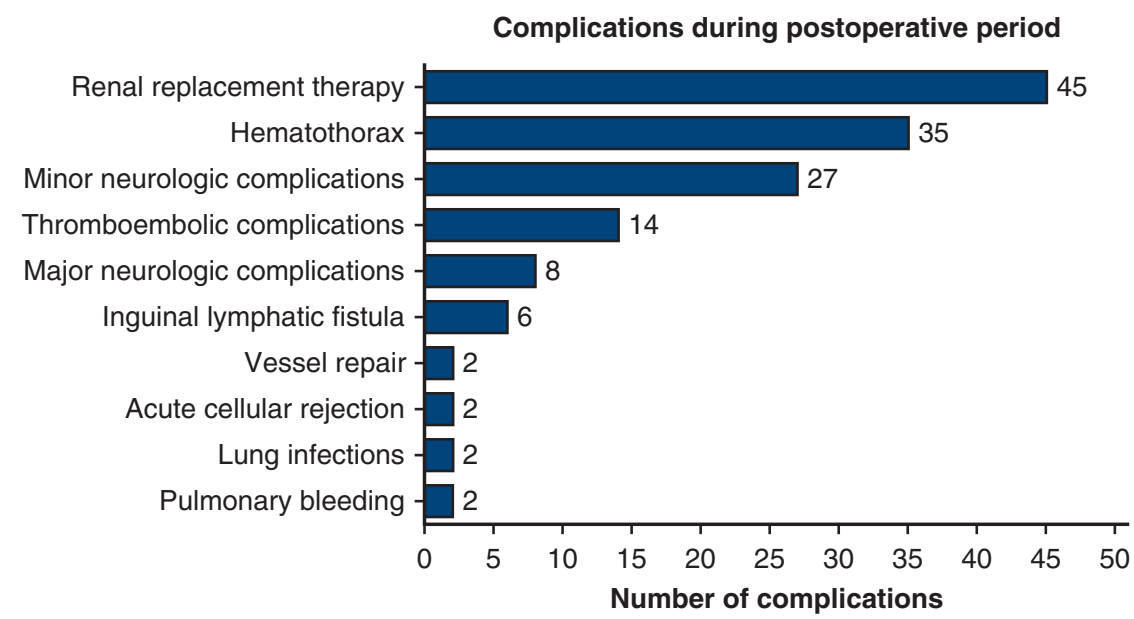

FIGURE E4. Complications in the postoperative period. Thirty-five patients (33\%) had a hemothorax after lung transplantation, and 45 patients $(42 \%)$ required temporary renal replacement therapy. In 27 patients, transient neurologic impairments were reported. The group minor neurologic complications included polyneuropathy, posterior reversible encephalopathy syndrome, and postoperative organic syndrome. One of our patients had a cerebral embolism after transplantation. Eight patients had some major neurologic complications: 4 cases of reversible paresis and 4 cases of epileptic seizures. Six patients developed lymphatic fistula at the cannulation site; all of them were successfully corrected surgically. Thrombotic and embolic complications include 1 case of cerebral embolization (upper body cannulation) and 1 case of thrombotic thrombocytopenic purpura. Twelve ECLS-related vessel occlusions were successfully reopened by Fogarty embolectomy. 
TABLE E1. Extracorporeal life support modalities were used according to the physiologic impairment

\begin{tabular}{|c|c|c|c|c|c|}
\hline & $\begin{array}{l}\text { Hypercapnic } \\
\text { failure }\end{array}$ & $\begin{array}{l}\text { Hypoxemic } \\
\text { failure }\end{array}$ & $\begin{array}{l}\text { Combined hemodynamic } \\
\text { and respiratory failure }\end{array}$ & $\begin{array}{c}\text { Biventricular } \\
\text { failure (PH) }\end{array}$ & $\begin{array}{c}\text { Pulmonary circulatory } \\
\text { bypass* }\end{array}$ \\
\hline \multicolumn{6}{|l|}{ ECCO2 Removal } \\
\hline iLA & + & - & - & - & - \\
\hline iLA-ActiVVe & + & + (mild hypoxia) & - & - & - \\
\hline Venovenous ECMO & + & + (severe hypoxia) & - & - & - \\
\hline Venoarterial ECMO & - & - & + & + & + \\
\hline PA/LA Novalung & - & - & - & - & + \\
\hline
\end{tabular}


TABLE E2. Group characteristics of propensity-matched cohorts and actual standardized mean differences for overall survival

\begin{tabular}{|c|c|c|c|}
\hline & ECLS-bridged patients & Controls & Standardized differences \\
\hline Diagnosis & & & 0.156 \\
\hline COPD & $3(3.1 \%)$ & $8(2.1 \%)$ & \\
\hline Interstitial lung disease & $23(24 \%)$ & $94(24.5 \%)$ & \\
\hline $\mathrm{CF}$ & $38(39.6 \%)$ & $156(40.6 \%)$ & \\
\hline PAH & $5(5.2 \%)$ & $23(6 \%)$ & \\
\hline CLAD & $13(13.5 \%)$ & $41(10.7 \%)$ & \\
\hline Others & $14(14.6 \%)$ & $62(16.2 \%)$ & \\
\hline Age (IQR, min-max) & $32(24-47,8-68)$ & $35(22-49,3-72)$ & -0.004 \\
\hline Female gender & $53(55.2 \%)$ & $213(55.5 \%)$ & -0.005 \\
\hline Year of Tx & & & -0.021 \\
\hline 1998 & $1(1 \%)$ & $0(0 \%)$ & \\
\hline 2000 & $0(0 \%)$ & $3(0.8 \%)$ & \\
\hline 2001 & $1(1 \%)$ & $2(0.5 \%)$ & \\
\hline 2002 & $0(0 \%)$ & $5(1.3 \%)$ & \\
\hline 2003 & $1(1 \%)$ & $9(2.3 \%)$ & \\
\hline 2004 & $0(0 \%)$ & $11(2.9 \%)$ & \\
\hline 2005 & $1(1 \%)$ & $5(1.3 \%)$ & \\
\hline 2006 & $4(4.2 \%)$ & $13(3.4 \%)$ & \\
\hline 2007 & $2(2.1 \%)$ & $10(2.6 \%)$ & \\
\hline 2008 & $3(3.1 \%)$ & $20(5.2 \%)$ & \\
\hline 2009 & $9(9.4 \%)$ & $18(4.7 \%)$ & \\
\hline 2010 & $14(14.6 \%)$ & $28(7.3 \%)$ & \\
\hline 2011 & $7(7.3 \%)$ & $36(9.4 \%)$ & \\
\hline 2012 & $9(9.4 \%)$ & $28(7.3 \%)$ & \\
\hline 2013 & $8(8.3 \%)$ & $30(7.8 \%)$ & \\
\hline 2014 & $13(13.5 \%)$ & $47(12.3 \%)$ & \\
\hline 2015 & $9(9.4 \%)$ & $45(11.7 \%)$ & \\
\hline 2016 & $10(10.4 \%)$ & $48(12.5 \%)$ & \\
\hline 2017 & $4(4.2 \%)$ & $25(6.5 \%)$ & \\
\hline Bridging goal & & & +0.088 \\
\hline Primary LTx & $83(86.5 \%)$ & $343(89.3 \%)$ & \\
\hline Elective ReTx & $13(13.5 \%)$ & $41(10.7 \%)$ & \\
\hline Type of Tx & & & 0.031 \\
\hline DLuTx & $93(96.9 \%)$ & $374(97.4 \%)$ & \\
\hline SLuTx & $3(3.1 \%)$ & $10(2.6 \%)$ & \\
\hline PreTx colonization with multiresistant bacteria & $23(24 \%)$ & $78(20.4 \%)$ & +0.081 \\
\hline PreTx colonization with Aspergillus & 0 & 0 & $<0.001$ \\
\hline PreTx kidney insufficiency & $4(4.2 \%)$ & $15(3.9 \%)$ & +0.013 \\
\hline PreTx pulmonary hypertension & $12(12.5 \%)$ & $44(11.5 \%)$ & +0.032 \\
\hline High CMV risk $\left(\mathrm{D}^{+} / \mathrm{R}^{-}\right)$ & $18(18.2 \%)$ & $59(15.4 \%)$ & +0.035 \\
\hline
\end{tabular}

For metric and dichotomous variables, the actual value has a plus sign if the ECLS group has larger values and a minus sign if the control group has larger values. In case of categorical variables with multiple levels, no sign was added. $E C L S$, Extracorporeal life support; $C O P D$, chronic obstructive pulmonary disease; $C F$, cystic fibrosis; $P A H$, pulmonary arterial hypertension; $C L A D$, chronic lung allograft dysfunction; $I Q R$, interquartile range; $T x$, transplantation; $L T x$, lung transplant; ReTx, retransplantation; $D L u T x$, double lung transplant; $S L u T x$, single lung transplant; PreTx, pretransplantation; $C M V$, cytomegalovirus; $D$, donor; $R$, recipient. 
TABLE E3. Group characteristics of propensity-matched cohorts and actual standardized mean differences for survival conditional to 90 days

\begin{tabular}{|c|c|c|c|}
\hline & ECLS-bridged patients & Controls & Standardized differences \\
\hline Diagnosis & & & 0.134 \\
\hline COPD & $3(3.8 \%)$ & $8(2.6 \%)$ & \\
\hline Interstitial lung disease & $19(24.4 \%)$ & $76(24.4 \%)$ & \\
\hline $\mathrm{CF}$ & $30(38.8 \%)$ & $124(39.7 \%)$ & \\
\hline PAH & $6(7.5 \%)$ & $25(8 \%)$ & \\
\hline CLAD & $11(14.1 \%)$ & $39(12.5 \%)$ & \\
\hline Others & $10(12.8 \%)$ & $40(12.9 \%)$ & \\
\hline Age (IQR, min-max) & $32(24-44,8-68)$ & $34(21-48,5-71)$ & -0.017 \\
\hline Female gender & $43(55.1 \%)$ & $173(55.4 \%)$ & -0.006 \\
\hline Year of Tx & & & -0.004 \\
\hline 1998 & $1(1.3 \%)$ & $3(1 \%)$ & \\
\hline 1999 & $0(0 \%)$ & $3(1 \%)$ & \\
\hline 2000 & $0(0 \%)$ & $1(0.3 \%)$ & \\
\hline 2001 & $0(0 \%)$ & $3(1 \%)$ & \\
\hline 2002 & $0(0 \%)$ & $2(0.6 \%)$ & \\
\hline 2003 & $1(1.3 \%)$ & $3(1 \%)$ & \\
\hline 2004 & $0(0 \%)$ & $11(3.5 \%)$ & \\
\hline 2005 & $1(1.3 \%)$ & $3(1 \%)$ & \\
\hline 2006 & $3(3.8 \%)$ & $9(2.9 \%)$ & \\
\hline 2007 & $2(2.5 \%)$ & $4(1.3 \%)$ & \\
\hline 2008 & $2(2.5 \%)$ & $11(3.5 \%)$ & \\
\hline 2009 & $6(7.5 \%)$ & $17(5.5 \%)$ & \\
\hline 2010 & $10(12.5 \%)$ & $23(7.4 \%)$ & \\
\hline 2011 & $6(7.5 \%)$ & $21(6.8 \%)$ & \\
\hline 2012 & $9(11.3 \%)$ & $27(8.7 \%)$ & \\
\hline 2013 & $6(7.5 \%)$ & $29(9.3 \%)$ & \\
\hline 2014 & $8(10 \%)$ & $41(13.2 \%)$ & \\
\hline 2015 & $8(10 \%)$ & $41(13.2 \%)$ & \\
\hline 2016 & $12(15 \%)$ & $50(16.1 \%)$ & \\
\hline 2017 & $5(6.3 \%)$ & $9(2.9 \%)$ & \\
\hline \multicolumn{4}{|l|}{ Bridging goal } \\
\hline Primary LTx & $273(87.5 \%)$ & $67(85.9 \%)$ & +0.047 \\
\hline Elective ReTx & $39(12.5 \%)$ & $11(14.1 \%)$ & \\
\hline \multicolumn{4}{|l|}{ Type of Tx } \\
\hline DLuTx & $308(98.7 \%)$ & 77 (98.7\%) & $<0.001$ \\
\hline SLuTx & $4(1.3 \%)$ & $1(1.3 \%)$ & \\
\hline $\begin{array}{l}\text { PreTx colonization with } \\
\text { multiresistant bacteria }\end{array}$ & $73(23.5 \%)$ & $20(25 \%)$ & +0.031 \\
\hline $\begin{array}{l}\text { PreTx colonization with } \\
\text { Aspergillus }\end{array}$ & 0 & 0 & $<0.001$ \\
\hline PreTx kidney insufficiency & $4(4.2 \%)$ & $3(3.8 \%)$ & +0.053 \\
\hline $\begin{array}{l}\text { PreTx pulmonary } \\
\text { hypertension }\end{array}$ & $45(14.5 \%)$ & $10(12.5 \%)$ & +0.019 \\
\hline High CMV risk $\left(\mathrm{D}^{+} / \mathrm{R}^{-}\right)$ & $18(18.2 \%)$ & $59(15.4 \%)$ & +0.008 \\
\hline
\end{tabular}

For metric and dichotomous variables, the actual value has a plus sign if the ECLS group has larger values and a minus sign if the control group has larger values. In case of categorical variables with multiple levels, no sign was added. $E C L S$, Extracorporeal life support; $C O P D$, chronic obstructive pulmonary disease; $C F$, cystic fibrosis; $P A H$, pulmonary arterial hypertension; $C L A D$, chronic lung allograft dysfunction; $I Q R$, interquartile range; $T x$, transplantation; $L T x$, lung transplant; ReTx, retransplantation; $D L u T x$, double lung transplant; $S L u T x$, single lung transplant; PreTx, pretransplantation; $C M V$, cytomegalovirus; $D$, donor; $R$, recipient. 
TABLE E4. Group characteristics of extracorporeal life support-bridged patients compared with nonbridged patients

\begin{tabular}{|c|c|c|c|}
\hline & Bridged patients $(\mathrm{n}=99)$ & Controls $(n=1555)$ & $P$ value \\
\hline Diagnosis & & & $<.001$ \\
\hline COPD & $3(3 \%)$ & $601(38.6 \%)$ & \\
\hline Interstitial lung disease & $23(23.2 \%)$ & $324(20.8 \%)$ & \\
\hline $\mathrm{CF}$ & $40(40.4 \%)$ & $280(18 \%)$ & \\
\hline PAH & $10(10.1 \%)$ & $134(8.6 \%)$ & \\
\hline CLAD & $13(13.1 \%)$ & $72(4.6 \%)$ & \\
\hline Others & $10(10.1 \%)$ & $144(9.3 \%)$ & \\
\hline Median age, y (IQR, min-max) & $32(24-45,8-68)$ & $49(33-58,1-74)$ & $<.001$ \\
\hline Male gender & $45(45.5 \%)$ & $817(52.5 \%)$ & .171 \\
\hline Year of LTx & & & $<.001$ \\
\hline 1998 & $1(1 \%)$ & $50(3.2 \%)$ & \\
\hline 1999 & $0(0 \%)$ & $55(3.5 \%)$ & \\
\hline 2000 & $0(0 \%)$ & $47(3 \%)$ & \\
\hline 2001 & $1(1 \%)$ & $43(2.8 \%)$ & \\
\hline 2002 & $0(0 \%)$ & $63(4.1 \%)$ & \\
\hline 2003 & $1(1 \%)$ & $64(4.1 \%)$ & \\
\hline 2004 & $0(0 \%)$ & $65(4.2 \%)$ & \\
\hline 2005 & $1(1 \%)$ & $77(5 \%)$ & \\
\hline 2006 & $4(4 \%)$ & $86(5.5 \%)$ & \\
\hline 2007 & $2(2 \%)$ & $65(4.2 \%)$ & \\
\hline 2008 & $3(3 \%)$ & $102(6.6 \%)$ & \\
\hline 2009 & $9(9.1 \%)$ & $84(5.4 \%)$ & \\
\hline 2010 & $14(14.1 \%)$ & $86(5.5 \%)$ & \\
\hline 2011 & $7(7.1 \%)$ & $101(6.5 \%)$ & \\
\hline 2012 & $9(9.1 \%)$ & $104(6.7 \%)$ & \\
\hline 2013 & $8(8.1 \%)$ & $111(7.1 \%)$ & \\
\hline 2014 & $13(13.1 \%)$ & $107(6.9 \%)$ & \\
\hline 2015 & $9(9.1 \%)$ & $105(6.8 \%)$ & \\
\hline 2016 & $12(12.1 \%)$ & $89(5.7 \%)$ & \\
\hline 2017 & $5(5.1 \%)$ & $51(3.3 \%)$ & \\
\hline Bridging goal & & & $<.001$ \\
\hline Primary LTx & $86(86.9 \%)$ & $1483(95.4 \%)$ & \\
\hline Elective ReTx & $13(13.1 \%)$ & $72(4.6 \%)$ & \\
\hline Type of Tx & & & $<.001$ \\
\hline DLTx & $39(39.4 \%)$ & $793(51 \%)$ & \\
\hline SLTx & $2(2 \%)$ & $196(12.6 \%)$ & \\
\hline Size-reduced & $27(27.3 \%)$ & $369(23.7 \%)$ & \\
\hline Lobar or split & $31(31.3 \%)$ & $197(12.7 \%)$ & \\
\hline PreTx colonization with multi-resistant bacteria & $26(26.3 \%)$ & $94(6 \%)$ & $<.001$ \\
\hline PreTx colonization with Aspergillus & 0 & $34(2.2 \%)$ & .320 \\
\hline PreTx kidney insufficiency & $4(4.2 \%)$ & $41(2.6 \%)$ & .405 \\
\hline PreTx pulmonary hypertension & $10(10.1 \%)$ & $224(14.4 \%)$ & .529 \\
\hline High $C M V$ risk $\left(D^{+} / R^{-}\right)$ & $229(14.7 \%)$ & $18(18.2 \%)$ & .360 \\
\hline PreTx diabetes mellitus & & & .417 \\
\hline IDDM & $7(7.1 \%)$ & $70(4.5 \%)$ & \\
\hline NIDDM & 0 & $6(0.4 \%)$ & \\
\hline Induction therapy & & & .012 \\
\hline No & $46(46.5 \%)$ & $721(46.4 \%)$ & \\
\hline ATG & $5(5.1 \%)$ & $258(16.6 \%)$ & \\
\hline ECP & $1(1 \%)$ & $8(0.5 \%)$ & \\
\hline Alemtuzumab & $47(47.5 \%)$ & $568(36.5 \%)$ & \\
\hline
\end{tabular}

Bold indicates statistical significance. $C O P D$, Chronic obstructive pulmonary disease; $C F$, cystic fibrosis; $P A H$, pulmonary arterial hypertension; $C L A D$, chronic lung allograft dysfunction; $I Q R$, interquartile range; $L T x$, lung transplantation; ReTx, retransplantation; $D L T x$, double lung transplantation; $S L T x$, single lung transplantation; PreTx, pretransplantation; $C M V$, cytomegalovirus; $D$, donor; $R$, recipient; IDDM, insulin-dependent diabetes mellitus; NIDDM, noninsulin-dependent diabetes mellitus; $A T G$, antithymocyte globulin; $E C P$, extracorporeal photopheresis. 
TABLE E5. Causes of death

\begin{tabular}{|c|c|c|c|}
\hline & Death during ECLS bridging $(\mathrm{n}=13)$ & In-hospital death $(n=28)$ & Long-term survivors $(n=18)$ \\
\hline Causes of death & $\begin{array}{c}\text { MOF } \\
5(38.5 \%) \\
\text { Sepsis } \\
2(15.4 \%) \\
\text { Cardiovascular } \\
2(15.4 \%) \\
\text { Cranial bleeding } \\
2(15.4 \%) \\
\text { Primary graft failure } \\
1(7.7 \%) \\
\text { Respiratory failure } \\
1(7.7 \%)\end{array}$ & $\begin{array}{c}\text { Sepsis } \\
13(46.4 \%) \\
\text { Graft failure } \\
5(17.9 \%) \\
\text { Infection not CMV } \\
3(10.7 \%) \\
\text { MOF } \\
3(10.7 \%) \\
\text { Cardiovascular } \\
2(7.1 \%) \\
\text { Malignancy } \\
1(3.6 \%) \\
\text { Cranial bleeding } \\
1(3.6 \%)\end{array}$ & $\begin{array}{c}\text { Infection not CMV } \\
5(27.8 \%) \\
\text { Sepsis } \\
3(16.7 \%) \\
\text { BO } \\
3(16.7 \%) \\
\text { Malignancy } \\
2(11.1 \%) \\
\text { Cardiovascular } \\
2(11.1 \%) \\
\text { MOF } \\
1(5.6 \%) \\
\text { Graft failure } \\
1(5.6 \%) \\
\text { CMV infection } \\
1(5.6 \%)\end{array}$ \\
\hline
\end{tabular}

Losses were grouped into patients who died during ECLS bridging, in-hospital deaths after transplantation, and patients who died during long-term follow-up. ECLS, Extracorporeal life support; $M O F$, multiorgan failure; $C M V$, cytomegalovirus; $B O$, bronchiolitis obliterans. 
TABLE E6. Comparison of patient characteristics of patients who died during bridging, early post-transplant deaths, and long-term survivors

\begin{tabular}{|c|c|c|c|c|}
\hline & $\begin{array}{c}\text { Deaths during } \\
\text { bridging }(n=13)\end{array}$ & $\begin{array}{l}\text { In-hospital deaths after } \\
\text { transplantation }(\mathbf{n}=\mathbf{2 8})\end{array}$ & $\begin{array}{c}\text { Long-term } \\
\text { survivors }(n=79) \\
\end{array}$ & $P$ value \\
\hline Median age, y (IQR, min-max) & $34(23-43,16-64)$ & $38(29-53,15-66)$ & $32(24-43,8-68)$ & .227 \\
\hline \multicolumn{5}{|l|}{ Gender } \\
\hline Male & $6(46.2 \%)$ & $13(46.4 \%)$ & $32(40.5 \%)$ & \multirow[t]{2}{*}{.828} \\
\hline Female & $7(53.8 \%)$ & $15(53.6 \%)$ & $47(59.5 \%)$ & \\
\hline \multicolumn{5}{|l|}{ Underlying diagnosis } \\
\hline COPD & 0 & $1(3.6 \%)$ & $2(2.5 \%)$ & \multirow[t]{8}{*}{.12} \\
\hline Interstitial lung disease & $3(23.1 \%)$ & $6(21.4 \%)$ & $20(25.3 \%)$ & \\
\hline $\mathrm{CF}$ & $5(38.5 \%)$ & $10(35.7 \%)$ & $29(36.7 \%)$ & \\
\hline PAH & 0 & $1(3.6 \%)$ & $10(12.7 \%)$ & \\
\hline ARDS & $2(15.4 \%)$ & $1(3.6 \%)$ & $4(5.1 \%)$ & \\
\hline CLAD & $3(23.1 \%)$ & $3(10.7 \%)$ & $10(12.7 \%)$ & \\
\hline POF & 0 & $6(21.4 \%)$ & $2(2.5 \%)$ & \\
\hline Others & 0 & 0 & $2(2.5 \%)$ & \\
\hline \multicolumn{5}{|l|}{ Bridging goal } \\
\hline Bridge to primary LTx & $10(76.9 \%)$ & $19(67.9 \%)$ & $67(84.8 \%)$ & \multirow[t]{3}{*}{.008} \\
\hline Bridge to elective ReTx & $3(23.1 \%)$ & $3(10.7 \%)$ & $10(12.7 \%)$ & \\
\hline Bridge to acute ReTx & $\mathbf{0}$ & $6(21.4 \%)$ & $2(2.5 \%)$ & \\
\hline \multicolumn{5}{|l|}{ Bridging indication } \\
\hline Hypoxic respiratory failure & $2(15.4 \%)$ & $7(25 \%)$ & $19(24 \%)$ & \multirow[t]{3}{*}{.895} \\
\hline Hypercapnic respiratory failure & $9(69.2 \%)$ & $19(67.9 \%)$ & $53(67 \%)$ & \\
\hline Combined hemodynamic and respiratory failure & $2(15.4 \%)$ & $2(7.1 \%)$ & $7(9 \%)$ & \\
\hline \multicolumn{5}{|l|}{ Ventilation before bridging } \\
\hline IV & $10(76.9 \%)$ & $23(82.1 \%)$ & $57(72.2 \%)$ & \multirow[t]{2}{*}{.569} \\
\hline NIV & $3(23.1 \%)$ & $5(17.9 \%)$ & $22(27.8 \%)$ & \\
\hline Tracheostomy before bridging & $2(15 \%)$ & $4(14 \%)$ & $18(23 \%)$ & .569 \\
\hline Median $\mathrm{PCO}_{2}$ before bridging (IQR, min-max) & $72(62-72,41-177)$ & $93(67-145,28.5-173)$ & $90(70-116,27-180)$ & .305 \\
\hline Median $\mathrm{Po}_{2} / \mathrm{FIO}_{2}$ ratio before bridging (IQR, min-max) & $72(60-138,43-247)$ & $95(69-121,40-266)$ & $119(70-170,44-407)$ & .206 \\
\hline Median $\mathrm{pH}$ ratio before bridging (IQR, min-max) & $7.3(7.1-7.4,6.9-7.5)$ & $7.2(7-7.4,6.9-7.5)$ & $7.3(7.2-7.4,6.9-7.6)$ & .569 \\
\hline Weaning from mechanical ventilation & $\mathbf{0}$ & $1(4 \%)$ & $14(23.7 \%)$ & .027 \\
\hline \multicolumn{5}{|l|}{ Awake status } \\
\hline Deeply sedated & $12(92.3 \%)$ & $26(92.9 \%)$ & $49(62 \%)$ & \multirow[t]{2}{*}{.002} \\
\hline Awake & $1(7.7 \%)$ & $2(7.1 \%)$ & $30(38 \%)$ & \\
\hline \multicolumn{5}{|l|}{ Bridging modalities } \\
\hline VV single-site ECMO & $1(7.7 \%)$ & $2(7.1 \%)$ & $7(8.9 \%)$ & \multirow[t]{7}{*}{.234} \\
\hline VV double-site ECMO & $2(15.4 \%)$ & $8(28.6 \%)$ & $21(26.6 \%)$ & \\
\hline VA & $5(38.5 \%)$ & $11(39.3 \%)$ & $20(25.3 \%)$ & \\
\hline iLA & 0 & $2(71 \%)$ & $7(8.9 \%)$ & \\
\hline iLA-ActiVVe & 0 & $2(7.1 \%)$ & $15(19 \%)$ & \\
\hline V-AV ECMO & 0 & 0 & $1(1.3 \%)$ & \\
\hline Combination of different modalities & $5(38.5 \%)$ & $3(10.7 \%)$ & $8(10.1 \%)$ & \\
\hline Median ECLS bridging (d) (IQR, min-max) & $10(6-15,3-28)$ & $4(2-7,1-37)$ & $5(3-9,1-80)$ & .014 \\
\hline
\end{tabular}

Bold indicates statistical significance. $I Q R$, Interquartile range; $C O P D$, chronic obstructive pulmonary disease; $C F$, cystic fibrosis; $P A H$, pulmonary arterial hypertension; $A R D S$, acute respiratory distress syndrome; $C L A D$, chronic lung allograft dysfunction; $P O F$, primary organ failure; $L T x$, lung transplantation; ReTx, retransplantation; $I V$, invasive ventilation; $\mathrm{NIV}$, noninvasive ventilation; $\mathrm{PCO}_{2}$, carbon dioxide tension; $\mathrm{PO}_{2}$, oxygen tension; $\mathrm{FIO}_{2}$, inspired oxygen fraction; $\mathrm{VV}$, venovenous; $E C M O$, extracorporeal membrane oxygenation; $V A$, venoarterial; $i L A$, interventional lung assist; $V-A V$, veno-arteriovenous; $E C L S$, extracorporeal life support. 
TABLE E7. Univariate Cox regression of risk factors for mortality by intention-to-treat

\begin{tabular}{|c|c|c|c|c|}
\hline \multirow[b]{2}{*}{ Variable } & \multirow[b]{2}{*}{$P$ value } & \multirow[b]{2}{*}{ HR } & \multicolumn{2}{|c|}{$95 \%$ CI } \\
\hline & & & Lower & $\overline{\text { Upper }}$ \\
\hline \multicolumn{5}{|l|}{ Diagnosis } \\
\hline COPD & Ref & & & \\
\hline Interstitial lung disease & .578 & 1.782 & 0.233 & 13.648 \\
\hline $\mathrm{CF}$ & .649 & 1.599 & 0.212 & 12.032 \\
\hline PPH & .967 & 0.954 & 0.099 & 9.180 \\
\hline ARDS & .689 & 1.587 & 0.165 & 15.268 \\
\hline CLAD & .308 & 2.902 & 0.374 & 22.526 \\
\hline POF & .168 & 4.437 & 0.533 & 36.951 \\
\hline Others & .630 & 1.980 & 0.123 & 31.817 \\
\hline Male & .127 & 1.512 & 0.889 & 2.572 \\
\hline \multicolumn{5}{|l|}{ Bridging goal } \\
\hline Bridge to primary LTx & Ref & & & \\
\hline Bridge to elective ReTx & .068 & 1.868 & 0.954 & 3.657 \\
\hline Bridge to acute ReTx & .017 & 2.856 & 1.206 & 6.767 \\
\hline \multicolumn{5}{|l|}{ Bridging indication } \\
\hline Hypoxic respiratory failure & .721 & 0.809 & 0.253 & 2.587 \\
\hline Hypercapnic respiratory failure & .613 & 1.304 & 0.466 & 3.646 \\
\hline Combined hemodynamic and respiratory failure & Ref & & & \\
\hline Invasive ventilation before LTx & .245 & 1.480 & 0.764 & 2.867 \\
\hline Tracheostomy before bridging & .300 & 0.695 & 0.349 & 1.382 \\
\hline $\mathrm{PCO}_{2}$ before bridging & .489 & 1.003 & 0.995 & 1.011 \\
\hline $\mathrm{PO}_{2} / \mathrm{FIO}_{2}$ ratio before bridging & .210 & 0.997 & 0.994 & 1.001 \\
\hline $\mathrm{pH}$ before bridging & .224 & 0.294 & 0.041 & 2.117 \\
\hline Weaning from mechanical ventilation & .110 & 0.469 & 0.185 & 1.188 \\
\hline Awake status & .008 & 0.381 & 0.186 & 0.779 \\
\hline ECLS bridging time & .741 & 1.094 & 0.642 & 1.866 \\
\hline \multicolumn{5}{|l|}{ Bridging modalities } \\
\hline VV single-site ECMO & .339 & 0.562 & 0.173 & 1.832 \\
\hline VV double-site ECMO & .163 & 0.540 & 0.227 & 1.284 \\
\hline VA & .675 & 0.846 & 0.386 & 1.853 \\
\hline iLA & .123 & 0.356 & 0.096 & 1.323 \\
\hline iLA-ActiVVe & .123 & 0.442 & 0.157 & 1.248 \\
\hline V-AV ECMO & .977 & 0.000 & 0.000 & \\
\hline Combination of different modalities & Ref & & & \\
\hline \multicolumn{5}{|l|}{ Era } \\
\hline First & Ref & & & \\
\hline Second & .389 & 0.703 & 0.316 & 1.567 \\
\hline Third & .023 & 0.393 & 0.176 & 0.881 \\
\hline
\end{tabular}

Bold indicates statistical significance. $H R$, Hazard ratio; $C I$, confidence interval; $C O P D$, chronic obstructive pulmonary disease; $C F$, cystic fibrosis; $P P H$, portopulmonary hypertension; $A R D S$, acute respiratory distress syndrome; $C L A D$, chronic lung allograft dysfunction; $P O F$, primary organ failure; $L T x$, lung transplantation; ReTx, retransplantation; $\mathrm{PCO}_{2}$, carbon dioxide tension; $\mathrm{PO}_{2}$, oxygen tension; $\mathrm{FIO}_{2}$, inspired oxygen fraction; $E C L S$, extracorporeal life support; $\mathrm{VV}$, venovenous; $E C M O$, extracorporeal membrane oxygenation; $V A$, venoarterial; $i L A$, interventional lung assist; $V-A V$, veno-arteriovenous. 
TABLE E8. Multivariable Cox regression of risk factors for mortality by intention-to treat

\begin{tabular}{lcccc}
\hline & & & \multicolumn{2}{c}{$\mathbf{9 5 \%}$ CI } \\
\cline { 5 - 5 } & $\boldsymbol{P}$ value & HR & Lower & Upper \\
\hline Age & .12 & 1.01 & 0.99 & 1.03 \\
Bridging goal & & & & \\
$\quad$ Bridge to primary LTx & Ref & & & \\
$\quad$ Bridge to elective ReTx & .51 & 1.72 & 0.33 & 8.91 \\
Bridge to acute ReTx &. $\mathbf{0 2}$ & $\mathbf{2 . 1 8}$ & $\mathbf{1 . 1 0}$ & $\mathbf{1 . 1 0}$ \\
Awake status & $\mathbf{. 0 1}$ & $\mathbf{0 . 3 7}$ & $\mathbf{0 . 1 8}$ & $\mathbf{0 . 7 9}$ \\
Era & & & & \\
$\quad$ First & Ref & & & \\
$\quad$ Second & .53 & 0.62 & 0.23 & 4.60 \\
$\quad$ Third & .96 & 1.03 & 0.14 & 2.78 \\
\hline Bold indicates statistical significance. $H R$, Hazard ratio; $C I$, confidence interval; $L T x$ \\
lung transplantation; ReTx, retransplantation.
\end{tabular}

